\title{
Dynamic Responses of Continuous Girder Bridges with Uniform Cross-Section under Moving Vehicular Loads
}

\author{
Qingfei Gao, ${ }^{1}$ Zonglin Wang, ${ }^{1}$ Hongyu Jia, ${ }^{2}$ Chenguang Liu, ${ }^{1}$ Jun Li, ${ }^{1,3}$ \\ Binqiang Guo, ${ }^{4}$ and Junfei Zhong ${ }^{1}$ \\ ${ }^{1}$ School of Transportation Science and Engineering, Harbin Institute of Technology, Harbin 150090, China \\ ${ }^{2}$ Department of Civil Engineering, Southwest Jiaotong University, Emei Campus, Emeishan 614202, China \\ ${ }^{3}$ School of Architecture Engineering and Technology, Heilongjiang College of Construction, Harbin 150050, China \\ ${ }^{4}$ Zhejiang Provincial Institute of Communications Planning, Design and Research, Hangzhou 310000, China
}

Correspondence should be addressed to Qingfei Gao; gaoqingfei_1986@163.com

Received 13 November 2014; Accepted 26 November 2014

Academic Editor: Yun-Bo Zhao

Copyright (C) 2015 Qingfei Gao et al. This is an open access article distributed under the Creative Commons Attribution License, which permits unrestricted use, distribution, and reproduction in any medium, provided the original work is properly cited.

\begin{abstract}
To address the drawback of traditional method of investigating dynamic responses of the continuous girder bridge with uniform cross-section under moving vehicular loads, the orthogonal experimental design method is proposed in this paper. Firstly, some empirical formulas of natural frequencies are obtained by theoretical derivation and numerical simulation. The effects of different parameters on dynamic responses of the vehicle-bridge coupled vibration system are discussed using our own program. Finally, the orthogonal experimental design method is proposed for the dynamic responses analysis. The results show that the effects of factors on dynamic responses are dependent on both the selected position and the type of the responses. In addition, the interaction effects between different factors cannot be ignored. To efficiently reduce experimental runs, the conventional orthogonal design is divided into two phases. It has been proved that the proposed method of the orthogonal experimental design greatly reduces calculation cost, and it is efficient and rational enough to study multifactor problems. Furthermore, it provides a good way to obtain more rational empirical formulas of the DLA and other dynamic responses, which may be adopted in the codes of design and evaluation.
\end{abstract}

\section{Introduction}

The dynamic response of bridges due to moving vehicular loads has been a subject of interest to engineers more than 100 years. Owning to the uncertain, transient, and nonlinear characteristics of the vehicle-bridge coupled vibration system, the phenomenon of dynamic response is one that requires fairly complex mathematical treatment to adequately characterize the motion and forces within the structure. However, for simplicity, it will instead be conceptual treatment using a common format, one that describes dynamic response as a fraction or multiple of the response that would be obtained if the same forces or loads were applied statically. This is, in fact, the same approach that most design specifications use to calculate the effects of dynamic live loading. When using such an approach, the amount of response above the static value is typically called the dynamic increment and is found by multiplying the static value by an "impact fraction." Alternatively, the total response can be expressed as a multiple of the static value using an impact factor [1]. In recognition of the complex behavior associated with the dynamic response from vehicular loading, several authors have observed that the term "impact" is too limited and therefore not descriptive of the actual behavior [2-5]. Instead, the current trend is to replace the term "impact fraction" with "dynamic load allowance," which represents the response from all types of vehicular dynamic effects, not solely impact. In this study, the term "dynamic load allowance" is adopted.

It has been proved that many different definitions of dynamic load allowance are adopted by various researchers and engineers $[6,7]$. Based on the design theory of the bridge 
in Chinese current code, the dynamic load allowance in this paper is defined as follows:

$$
\mu\left(x_{b}\right)=\frac{y_{d, \text { max }}\left(x_{b}, x_{v 1}\right)}{y_{s, \text { max }}\left(x_{b}, x_{v 2}\right)}-1,
$$

where $x_{b}$ is the location of the selected section, $\mu\left(x_{b}\right)$ denotes the dynamic load allowance of the selected section of the bridge, and $y_{d \text {, max }}\left(x_{b}, x_{v 1}\right)$ and $y_{s, \text { max }}\left(x_{b}, x_{v 2}\right)$, respectively, denote the maximum dynamic response and the maximum static response of the selected section. Furthermore, $x_{v 1}$ and $x_{v 2}$ mean the location of the vehicle when the dynamic response and the static response reach the maximum value. It should be noted that $x_{v 1}$ and $x_{v 2}$ are not the same in most of the time.

The dynamic response of a bridge to a crossing vehicle is a complex problem affected by the dynamic characteristics of both the bridge and the vehicle and by the bridge surface conditions [1]. Extensive research and development has been carried out to understand the vibration of bridges as a result of natural sources of vibration and to determine the dynamic allowance as a function of the fundamental frequency due to its uniqueness [8-11]. So it is important to find a reliable method to estimate the natural frequency of bridges. Komatsu et al. evaluated the natural vibration responses of straight and curved I- or box-girder bridges using Vlasov's beam theory [12, 13]. Cantieni conducted an experimental study to establish a reliable relationship between the fundamental frequency and maximum span length of bridges [14]. Meanwhile, Billing presented tables of natural frequencies for straight, continuous symmetric multispan uniform beams of two through six spans, for various span ratios [15]. Additionally, in order to reduce the significant difference between the estimation of the natural frequency obtained from the codes and theoretical methods or numerical simulation, Gao et al. proposed a numerical improved method for straight bridges [16, 17]. Also, the empirical expressions are established by Mohseni et al. using regression analysis, to determine the fundamental frequencies of skew continuous multicell box-girder bridges [18]. However, some limitations still exist for these methods to actually be used in practice.

Over the last 60 years, a significant amount of research has been conducted in the area of bridge dynamics, and this research has been both analytical and experimental in scope. Following the collapse of several railway bridges in Great Britain, the first study of vehicle-bridge interaction was conducted in 1849 by Willis [19]. A major experimental investigation of bridge impact loads was initiated in 1958 by American Association of State Highway Officials (AASHO). Eighteen simply supported bridges traversed by the two-axle trucks and the three-axle tractor-trailer combinations were investigated, each with a span of $15 \mathrm{~m}$ [20]. Wright and Green reported on a series of experimental investigations of vehiclebridge interaction made on 52 highway bridges in Ontario from 1956 to 1957 [21]. Csagoly et al. conducted a second series of tests on bridges (11 bridges) in Ontario in 1969 to 1971 [22]. Page [23] and Leonard [24] reported on a series of dynamic tests conducted on highway bridges (30 bridges) by the Transport and Road Research Laboratory (TRRL) in England. Shepard and Sidwell [25], Shepard and Aves [26], and Wood and Shepard [27] reported on fourteen bridge tests conducted in New Zealand. In 1980, a third series of dynamic testing of highway bridges in Ontario was performed. The tests were conducted on 27 bridges of various configurations of steel, concrete, and timber construction [5, 28]. Cantieni presented results from the dynamic load tests of 226 highway bridges in Switzerland from the mid-1950s to the early 1980s $[14,29]$. As for the numerical simulation, in 1970, Veletsos developed a numerical method for computing the dynamic response of highway bridges to moving vehicular loads [30]. Guant et al. investigated analytically the effects on bridge accelerations of several parameters, including the properties of the bridge and the vehicle as well as the initial conditions of the roadway [31]. Inbanathan and Wieland performed an analytical investigation of the dynamic response of a simply supported box girder bridge due to vehicle moving across the span [32]. Coussy et al. presented an analytical study of the influence of random surface irregularities on the dynamic response of bridges [33]. Recently, Bakht and Pinjarkar presented a literature review of bridge dynamics, with a particular focus on the dynamic testing of highway bridges [7]. And Paultre et al. presented a comprehensive review of analytical and experimental findings on bridge dynamics and the evaluation of the dynamic load allowance [19]. All these studies have proved that many of the parameters interact with one another, further complicating the issue, and consequently, many research studies have reported seemingly conflicting conclusions.

Therefore, the method of orthogonal experimental design in batches [34-38] has been proposed in this paper. It can be used for studying both the main effects and the interaction effects. Meanwhile, due to the processing in batches, it greatly reduces the calculation cost.

In this study, the natural frequencies of the simply supported girder bridge and the continuous girder bridge with uniform cross-section are firstly investigated based on the theoretical derivation and the numerical simulation. And then the effects of different parameters on the dynamic responses of the vehicle-bridge coupled vibration system are discussed by our own program VBCVA. Finally, the orthogonal experimental design method is proposed for the dynamic responses analysis, including the case without interaction and the case considering interaction.

\section{Natural Frequencies of Multispan Continuous Girder Bridges}

In civil and transportation engineering, dynamic characteristics of structures always consist of natural frequencies, corresponding vibration modes, and damping ratios. The natural frequency is one of the most important dynamic characteristics, due to its key role in determining dynamic responses of the structure under dynamic loads, such as wind, earthquake, and moving vehicles. Also, the impact factor or dynamic load allowance, which is used for considering the dynamic increments generated by moving vehicular loads, is 
TABLE 1: Three different types of boundary of single-span bridge.

\begin{tabular}{|c|c|c|c|}
\hline Boundary & Hinged and hinged & Fixed and hinged & Fixed and fixed \\
\hline Schematic plot & ाभगा & דim & \\
\hline \multirow{2}{*}{ Boundary description } & $\left\{\varphi_{n}(0)=0 \quad \varphi_{n}^{\prime \prime}(0)=0\right.$ & $\varphi_{n}(0)=0 \quad \varphi_{n}^{\prime}(0)=0$ & $\varphi_{n}(0)=0 \quad \varphi_{n}^{\prime}(0)=0$ \\
\hline & $\varphi_{n}(L)=0 \quad \varphi_{n}^{\prime \prime}(L)=0$ & $\varphi_{n}(L)=0 \quad \varphi_{n}^{\prime \prime}(L)=0$ & $\varphi_{n}(L)=0 \quad \varphi_{n}^{\prime}(L)=0$ \\
\hline
\end{tabular}

Note: $\varphi=0$ means the deflection is zero, $\varphi^{\prime}=0$ means the rotation is zero, and $\varphi^{\prime \prime}=0$ means the moment is zero.

TABLE 2: The results of single-span bridges with different boundary conditions.

\begin{tabular}{|c|c|c|c|}
\hline Boundary & Vibration modes & Frequency equation & First three frequencies \\
\hline Hinged and hinged & $\varphi_{n}(x)=A_{1} \sin \alpha_{n} x$ & $\sin \alpha_{n} L=0$ & $\begin{array}{r}\alpha_{1}=\frac{\pi}{L} \\
\alpha_{2}=\frac{2 \pi}{L} \\
\alpha_{3}=\frac{3 \pi}{L}\end{array}$ \\
\hline Fixed and hinged & $\begin{aligned} \varphi_{n}(x)=A_{1}\left[\sin \alpha_{n} x-\sinh \alpha_{n} x\right. \\
\\
\left.+\frac{\sinh \alpha_{n} L-\sin \alpha_{n} L}{\cos \alpha_{n} L-\cosh \alpha_{n} L}\left(\cos \alpha_{n} x-\cosh \alpha_{n} x\right)\right]\end{aligned}$ & $\tan \alpha_{n} L-\tanh \alpha_{n} L=0$ & $\begin{array}{l}\alpha_{1}=\frac{3.927}{L} \\
\alpha_{2}=\frac{7.069}{L} \\
\alpha_{3}=\frac{10.210}{L}\end{array}$ \\
\hline Fixed and fixed & $\begin{aligned} \varphi_{n}(x)=A_{1}\left[\sin \alpha_{n} x-\sinh \alpha_{n} x\right. \\
\\
\left.\quad+\frac{\cos \alpha_{n} L-\cosh \alpha_{n} L}{\sin \alpha_{n} L+\sinh \alpha_{n} L}\left(\cos \alpha_{n} x-\cosh \alpha_{n} x\right)\right]\end{aligned}$ & $3-2 \cos \alpha_{n} L \cosh \alpha_{n} L=0$ & $\begin{array}{l}\alpha_{1}=\frac{4.739}{L} \\
\alpha_{2}=\frac{7.853}{L} \\
\alpha_{3}=\frac{10.996}{L}\end{array}$ \\
\hline
\end{tabular}

given as the function of natural frequencies in most codes and specifications for bridge design. In addition, the serviceability of bridges, especially for pedestrian bridges, is closely related to the natural frequency. Therefore, the natural frequency is firstly studied in this paper, and it is the basis of dynamic responses analysis.

2.1. Simply Supported Girder Bridges. The boundary of the simply supported girder bridge is assumed as pinned joint in both ends. However, according to inspections of existing bridges, we found that the ends could not completely rotate with the degeneration of rubber bearings. For convenience of engineers and researchers, three types of boundary are investigated, which are shown in Table 1.

As for the Euler beam with uniform cross-section, if the damping is ignored, the vibration governing equation can be simplified as

$$
m \ddot{y}+E I \frac{\partial^{4} y}{\partial x^{4}}=p(x, t),
$$

where the $p$ denotes the force and $m, E, I, y, x$, and $t$ denote, respectively, the mass per unit length, elasticity modulus, moment of inertia, displacement, location, and time.
Based on the method of separation of variables, the solution can be listed as follows:

$$
\begin{gathered}
\omega_{n}=\alpha_{n}^{2} \sqrt{\frac{E I}{m}} \\
\varphi_{n}(x)=A_{1} \sin \alpha_{n} x+A_{2} \cos \alpha_{n} x \\
+A_{3} \sinh \alpha_{n} x+A_{4} \cosh \alpha_{n} x,
\end{gathered}
$$

where $\omega_{n}$ is the $n$th natural frequency $(\mathrm{rad} / \mathrm{s}), \varphi_{n}$ is the $n$th vibration mode, and $\alpha_{n}$ is the constant parameter determined by both the cross-section and the boundary conditions. In addition, $A_{1}, A_{2}, A_{3}$, and $A_{4}$ are constant parameters, which are determined by the boundary condition.

Submitting (4) into different types of boundaries in Table 1, then the results can be seen in Table 2.

It can be seen from Table 2 that the natural frequency is higher when there are more constraints and the corresponding stiffness is higher. The $n$th natural frequency of the single-span bridge with different boundary conditions can be summarized as

$$
f_{n}=\frac{\pi}{2}\left(\frac{n+0.25 b}{L}\right)^{2} \sqrt{\frac{E I}{m}},
$$


where $b$ is used for denoting different boundary conditions and $L$ is the span length. When the boundary is hinged and hinged, the parameter $b=0$. As for the other two conditions, $b=1$ and $b=2$ in turn.

For common bridges, the moment of inertia $I$ is positively correlated with the factor $h^{3}$ ( $h$ is the height of the beam), and the area $A$ is positively correlated with the hight $h$. Therefore, the $n$th natural frequency $f_{n}$ is negatively related to the span length $L$. And it successfully explains the phenomenon that most empirical formulas regressed by fielding test for estimating natural frequencies are negatively correlated with the span length $L$.

2.2. Continuous Girder Bridges with Uniform Spans. As for 2-span, 3-span, and 4-span continuous girder bridges with uniform cross-section and uniform spans, the natural frequency and corresponding vibration modes are given by Gao et al. [16]. Based on a similar method, more general frequency equation can be listed as follows:

$$
\mid \begin{array}{cccccc|c}
-2 G_{n} & H_{n} & 0 & \cdots & 0 & 0 & 1 \\
H_{n} & -2 G_{n} & H_{n} & \cdots & 0 & 0 & 2 \\
0 & H_{n} & -2 G_{n} & H_{n} & 0 & 0 & 3 \\
\vdots & \vdots & \ddots & \ddots & \ddots & \vdots & \vdots \\
0 & 0 & 0 & H_{n} & -2 G_{n} & H_{n} & n-1 \\
0 & 0 & 0 & \cdots & H_{n} & -2 G_{n} & n
\end{array}=0
$$

where

$$
\begin{aligned}
& G_{n}=\frac{\cosh \alpha_{n} L}{\sinh \alpha_{n} L}-\frac{\cos \alpha_{n} L}{\sin \alpha_{n} L}, \\
& H_{n}=\frac{1}{\sinh \alpha_{n} L}-\frac{1}{\sin \alpha_{n} L} .
\end{aligned}
$$

For common bridges, the number of spans is not more than eight. Equation (6) is solved by the general software MATLAB, and the frequency equations and the natural frequencies are listed in Tables 3 and 4.

It can be seen from Table 4 that the first natural frequency of the multispan continuous girder bridge with uniform spans is completely the same as that of the corresponding simply supported girder bridge. Also, for bridges with different spans, the fundamental vibration modes are retained. However, the number of other vibration modes among fundamental vibration modes is more for the bridge with more spans.

In the Chinese code D60-2004 for bridge design, the impact factor is defined as the function of the natural frequency. For continuous girder bridges, the impact factor of the positive moment in mid-span is different from that of the negative moment in pier-top section, which is determined by the curvature of different modes. According to the analysis of vibration modes distribution, for positive moment in midspan section, the first mode is significant for all bridges. However, for negative moment in pier-top section, the curvature of the second vertical vibration mode is larger for even-span bridges, and the curvature of the third vertical vibration mode is larger for odd-span bridges (Figure 1).
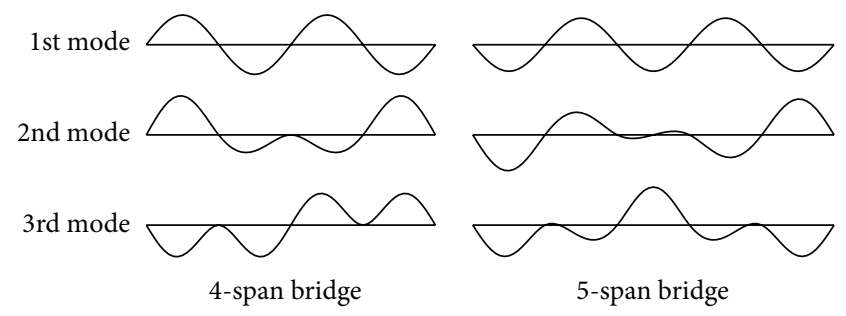

FIGURE 1: Vertical vibration modes distribution for bridges with different spans.

TABLE 3: Frequency equations of multispan continuous girder bridges with uniform spans.

\begin{tabular}{lc}
\hline Number of spans & Frequency equation \\
\hline 2 & $G_{n}=0$ \\
3 & $4 G_{n}^{2}-H_{n}^{2}=0$ \\
4 & $G_{n}\left(4 G_{n}^{2}-2 H_{n}^{2}\right)=0$ \\
5 & $16 G_{n}^{4}-12 G_{n}^{2} H_{n}^{2}+H_{n}^{4}=0$ \\
6 & $G_{n}\left(16 G_{n}^{4}-16 G_{n}^{2} H_{n}^{2}+3 H_{n}^{4}\right)=0$ \\
7 & $64 G_{n}^{6}-80 G_{n}^{4} H_{n}^{2}+24 G_{n}^{2} H_{n}^{4}-H_{n}^{6}=0$ \\
8 & $G_{n}\left(64 G_{n}^{6}-96 G_{n}^{4} H_{n}^{2}+40 G_{n}^{2} H_{n}^{4}-4 H_{n}^{6}\right)=0$ \\
\hline
\end{tabular}

So the second natural frequency in the even-span bridge and the third natural frequency in the odd-span bridge are selected for calculating the impact factor of negative moment in pier-top section. To make it clear, both of them are denoted as $f_{2}$. Based on Table 4, the empirical formula of $f_{2}$ can be given by

$$
f_{2}=\frac{1}{2 \pi}\left(\frac{\lambda \pi}{L}\right)^{2} \sqrt{\frac{E I}{m}}=\lambda^{2} \frac{\pi}{2 L^{2}} \sqrt{\frac{E I}{m}}
$$

where $\lambda$ is the modified factor, and it can be gained by

$$
\lambda= \begin{cases}1.25 & s=2 \\ 1+0.08 \times 2^{2-m} & s=2 m, \quad 2 \leq m \leq 4 \\ 1+0.36 \times 2^{2-m} & s=2 m-1, \quad 2 \leq m \leq 4,\end{cases}
$$

where $s$ is the number of spans.

2.3. Continuous Girder Bridges with Nonuniform Spans. The multispan continuous girder bridge is usually seen in urban areas and other areas with special terrain. For urban bridges, when the road extends under the bridge, the span above the road will be larger than others. For bridges in special terrain areas, the piers cannot be constructed at the idealized location due to the bad terrain occasionally, so the spans should be nonuniformly arranged.

To our experience of bridge design, the length of side span is always smaller in the multispan continuous girder bridge with nonuniform spans. The span ratio $r$ is introduced here. And it has been assumed that only the length of side span is different from others (Figure 2):

$$
r=\frac{L_{s}}{L_{m}}
$$


TABLE 4: Natural frequencies of multispan continuous girder bridges with uniform spans.

\begin{tabular}{lc}
\hline Number of spans & Natural frequencies $(\mathrm{Hz})$ \\
\hline $\begin{array}{l}2 \\
3\end{array}$ & $f_{n}=\frac{1}{2 \pi L^{2}}\left(\pi^{2}, 3.927^{2}, 4 \pi^{2}, \ldots\right) \sqrt{\frac{E I}{m}}$ \\
4 & $f_{n}=\frac{1}{2 \pi L^{2}}\left(\pi^{2}, 3.556^{2}, 4.298^{2}, 4 \pi^{2}, \ldots\right) \sqrt{\frac{E I}{m}}$ \\
5 & $f_{n}=\frac{1}{2 \pi L^{2}}\left(\pi^{2}, 3.393^{2}, 3.927^{2}, 4.463^{2}, 4 \pi^{2}, \ldots\right) \sqrt{\frac{E I}{m}}$ \\
6 & $f_{n}=\frac{1}{2 \pi L^{2}}\left(\pi^{2}, 3.309^{2}, 3.700^{2}, 4.153^{2}, 4.550^{2}, 4 \pi^{2}, \ldots\right) \sqrt{\frac{E I}{m}}$ \\
7 & $f_{n}=\frac{1}{2 \pi L^{2}}\left(\pi^{2}, 3.261^{2}, 3.556^{2}, 3.927^{2}, 4.298^{2}, 4.601^{2}, 4 \pi^{2}, \ldots\right) \sqrt{\frac{E I}{m}}$ \\
8 & $f_{n}=\frac{1}{2 \pi L^{2}}\left(\pi^{2}, 3.230^{2}, 3.460^{2}, 3.764^{2}, 4.089^{2}, 4.395^{2}, 4.634^{2}, 4 \pi^{2}, \ldots\right) \sqrt{\frac{E I}{m}}$ \\
\hline
\end{tabular}
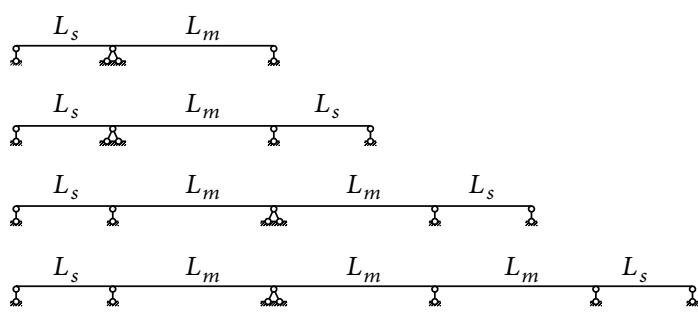

FIGURE 2: Schematic plots of multispan continuous girder bridges with nonuniform spans.

where $L_{s}$ is the length of side span and $L_{m}$ is the length of middle span. by

The frequency equation of this type of bridge can be given

$$
\begin{array}{cccccc|c}
-G_{n s}-G_{n m} & H_{n m} & 0 & \ldots & 0 & 0 & 1 \\
H_{n m} & -2 G_{n m} & H_{n m} & \ldots & 0 & 0 & 2 \\
0 & H_{n m} & -2 G_{n m} & H_{n m} & 0 & 0 & 3 \\
\vdots & \vdots & \ddots & \ddots & \ddots & \vdots & \vdots \\
0 & 0 & 0 & H_{n m} & -2 \dot{G}_{n m} & H_{n m} & n-1 \\
0 & 0 & 0 & \cdots & H_{n m} & -G_{n s}-G_{n m} & n
\end{array}
$$

When the number of spans is from 2 to 5 , the frequency equations are listed in Table 5.

The empirical formulas for estimating natural frequencies of the bridge with nonuniform spans are listed as

$$
\begin{aligned}
& f_{1}=\frac{1}{2 \pi}\left(\frac{\eta_{1} \pi}{L}\right)^{2} \sqrt{\frac{E I}{m}}, \\
& f_{2}=\frac{1}{2 \pi}\left(\frac{\eta_{2} \pi}{L}\right)^{2} \sqrt{\frac{E I}{m}},
\end{aligned}
$$

where $\eta_{1}$ and $\eta_{2}$ are modified factors, which can be seen in Figure 3.

It can be seen from Figure 3(a) that all of modified factors are not less than 1.0. In other words, the first natural frequency of the multispan continuous girder bridge is larger than that of the corresponding simply supported girder bridge.
TABLE 5: Frequency equations of multispan bridges with nonuniform spans.

\begin{tabular}{lc}
\hline $\begin{array}{l}\text { Number of } \\
\text { spans }\end{array}$ & Frequency equation \\
\hline 2 & $G_{n s}+G_{n m}=0$ \\
3 & $\left(G_{n s}+G_{n m}\right)^{2}-H_{n m}^{2}=0$ \\
4 & $\left(G_{n s}+G_{n m}\right)\left(G_{n m}^{2}+G_{n s} G_{n m}-H_{n m}^{2}\right)=0$ \\
5 & $G_{n s}^{2}\left(4 G_{n m}^{2}-H_{n m}^{2}\right)+G_{n s} G_{n m}\left(8 G_{n m}^{2}-6 H_{n m}^{2}\right)+$ \\
& $\left(4 G_{n m}^{4}-5 G_{n m}^{2} H_{n m}^{2}+H_{n m}^{4}\right)=0$ \\
\hline
\end{tabular}

Because the side span length is smaller than the middle span length, the stiffness has been increased by the side span. In addition, the modified factor $\eta_{1}$ of the bridge with two spans is completely the same as that of the bridge with four spans. This is due to the free rotation of the middle support of the bridge with four spans, and the first vibration mode of fourspan bridge is equal of that of two two-span bridges.

It can be seen from the Figure 3(b) that the modified factor $\eta_{2}$ of 4-span bridge is almost the same as that of 5-span bridge. They are largely different from others and should be noted.

Finally, it has been emphasized that the empirical formulas and modified factors proposed in this paper can be used for estimating natural frequencies of bridges with uniform cross-section. Also, according to these formulas, the factors influencing natural frequencies are more clearly seen, which may give a better guideline for the design and evaluation of dynamic performance of bridges.

\section{Dynamic Responses Analysis by Traditional Method}

Research over the last 40 years has shown that the dynamic responses of bridges under moving vehicles are influenced by many parameters, such as the dynamic characteristics of the vehicle, the dynamic characteristics of the bridge, and variations in the surface conditions of the bridge and 


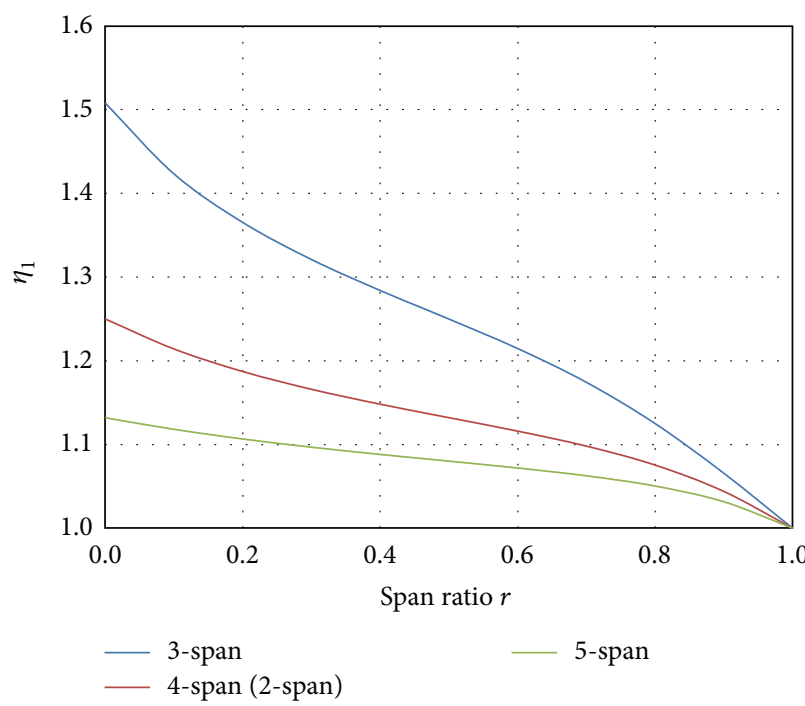

(a) Modified factor $\eta_{1}$

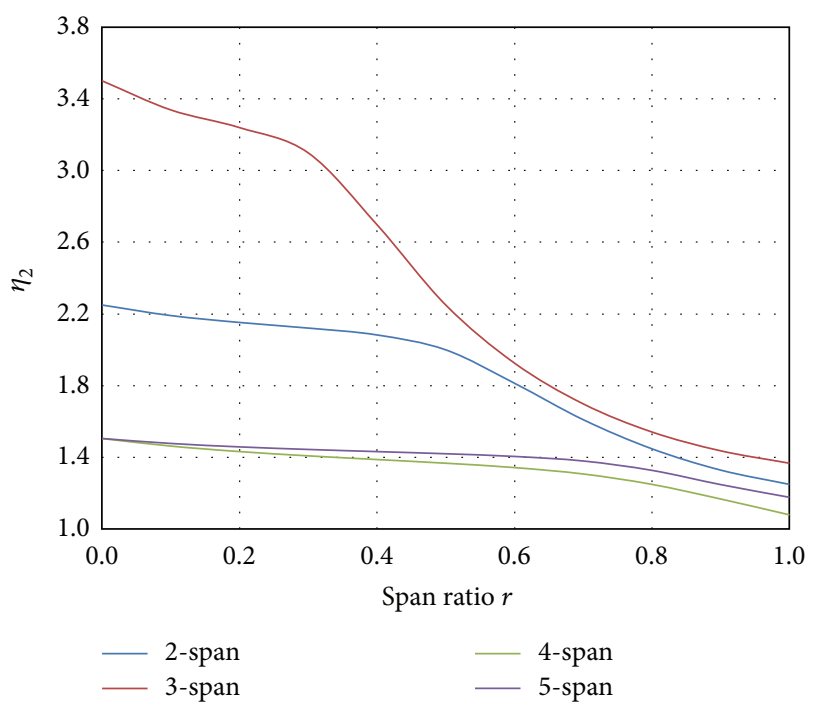

(b) Modified factor $\eta_{2}$

Figure 3: Modified factors of natural frequencies for the bridge with nonuniform spans.

approach roadways [1]. However, most of the studies focused on the dynamic load allowance in midspan of the bridge. In this part, the dynamic load allowances (DLAs) in the side span and the middle span are discussed, respectively, to obtain the differences of DLAs in variance sections. Also, for comfort analysis, the accelerations of the bridge and the vehicle are investigated.

Based on the existing research results, thirteen parameters are considered here. According to the traditional method, every parameter is studied, respectively. In other words, if this parameter is changing, all of the other parameters are fixed. Therefore, the fundamental model of bridge-vehicle coupled system is assumed at first, and then every parameter is varied from the basis of this model. They are listed in Tables 6, 7, and 8.

According to the numerical simulation, the effect of different parameters on the dynamic response of the vehiclebridge system is investigated by our own program VBCVA (Vehicle-Bridge Coupled Vibration Analysis). It has to be noted that the pavement roughness model proposed by Hwang and Nowak has been adopted in this program [39].

3.1. Effect of Roughness. For actual bridges, the pavement roughness is an inevitable factor. The effect of roughness on dynamic responses of the vehicle-bridge system is shown in Figure 4.

It can be seen from Figure 4 that, with the deterioration of bridge pavement conditions, the DLA of the bridge, the acceleration of the bridge, and the acceleration of the bridge grow in a linear fashion. Moreover, the dynamic response of the middle span is smaller than that of the side span. In addition, the growth rate in the middle span is a little smaller than that of the side span.

A great deal of research shows that the bridge pavement is one of the most vulnerable components due to its smaller stiffness [40, 41]. The results obtained from this study show that the roughness may significantly promote the vibration of the bridge traversed by moving vehicular loads. This will set up a vicious circle of increasing vibration, poorer roughness, and increased stress. Additionally, the larger vibration acceleration of the vehicle induced by the poorer roughness will make the passengers uncomfortable. Therefore, we should pay more attention to the bridge pavement condition in actual operation. Prompt repair of the damaged bridge pavement will reduce the unnecessary cost.

3.2. Effect of Span Length. As for the continuous girder bridges with uniform cross-section, the common span length ranges from $20 \mathrm{~m}$ to $40 \mathrm{~m}$. It has to be emphasized that the cross-sections of bridges with different span length are the same. The effect of span length on dynamic response of the vehicle-bridge system is shown in Figure 5.

It can be seen from Figure 5 that as the span length increases, the DLA of the middle span firstly decreases and then keeps steady, and the DLA of the side span is on the rise, which is largely different from the former one. But the change of the vibration acceleration in the middle span is the same as that of the vibration acceleration in the side span. Both of them slightly decrease and then increase. Additionally, the vibration acceleration of the vehicle rises at first and goes down later with the increasing of the span length.

For most dynamic responses in Figure 5, there is an extreme point with the increasing of the span length. It may be due to the resonance phenomenon between the bridge and the vehicle. The vibration natural frequency of the bridge with $25 \mathrm{~m}$ long span may be more close to that of the vehicle.

3.3. Effect of Span Ratio. From the aspect of mechanical characteristics due to the static load, the length of side span is not larger than that of middle span and not smaller than 
TABLE 6: Parameters of the bridge in the fundamental model.

\begin{tabular}{lccccccc}
\hline$L(\mathrm{~m})$ & $W(\mathrm{~m})$ & $I\left(\mathrm{~m}^{4}\right)$ & $A\left(\mathrm{~m}^{2}\right)$ & $E(\mathrm{MPa})$ & $\rho\left(\mathrm{kg} / \mathrm{m}^{3}\right)$ & $\xi$ & \multicolumn{1}{c}{${ }^{2}$} \\
\hline 40 & 12 & 3.54 & 7.08 & 34500 & 2600 & 0.05 & 2.0 \\
\hline
\end{tabular}

$L$ : length, $W$ : width, $I$ : moment of inertia, $E$ : modules of elasticity, $\rho$ : density, $\xi$ : damping ratio, and $X$ : maximum magnitude of the roughness.

TABLE 7: Parameters of the vehicle in the fundamental model.

\begin{tabular}{lc}
\hline Parameters & Value \\
\hline Mass of truck body & $31800 \mathrm{~kg}$ \\
Mass of front wheel & $400 \mathrm{~kg}$ \\
Mass of middle/rear wheel & $600 \mathrm{~kg}$ \\
Pitching moment of inertia & $40000 \mathrm{~kg} \cdot \mathrm{m}^{2}$ \\
Rolling moment of inertia & $10000 \mathrm{~kg} \cdot \mathrm{m}^{2}$ \\
Distance (front axle to center) & $4.60 \mathrm{~m}$ \\
Distance (middle axle to center) & $0.36 \mathrm{~m}$ \\
Distance (middle to rear axle) & $1.40 \mathrm{~m}$ \\
Wheel base & $1.80 \mathrm{~m}$ \\
Upper stiffness (front axle) & $1200 \mathrm{kN} \cdot \mathrm{m}^{-1}$ \\
Upper stiffness (middle/rear axle) & $2400 \mathrm{kN} \cdot \mathrm{m}^{-1}$ \\
Upper damping (front axle) & $5 \mathrm{kN} \cdot \mathrm{s} \cdot \mathrm{m}^{-1}$ \\
Upper damping (middle/rear axle) & $10 \mathrm{kN} \cdot \mathrm{s} \cdot \mathrm{m}^{-1}$ \\
Lower stiffness (front axle) & $2400 \mathrm{kN} \cdot \mathrm{m}^{-1}$ \\
Lower stiffness (middle/rear axle) & $4800 \mathrm{kN} \cdot \mathrm{m}^{-1}$ \\
Lower damping (front axle) & $6 \mathrm{kN} \cdot \mathrm{s} \cdot \mathrm{m}^{-1}$ \\
Lower damping (middle/rear axle) & $12 \mathrm{kN} \cdot \mathrm{s} \cdot \mathrm{m}^{-1}$ \\
Speed & $80 \mathrm{~km} / \mathrm{h}$ \\
\hline
\end{tabular}

TABle 8: Parameters description and their values.

\begin{tabular}{|c|c|c|c|}
\hline Index & Description & Values & Note \\
\hline A & Pavement roughness & $1 \mathrm{~cm}, 2 \mathrm{~cm}, 3 \mathrm{~cm}, 4 \mathrm{~cm}, 5 \mathrm{~cm}$ & Maximum magnitude \\
\hline B & Length of the main span & $20 \mathrm{~m}, 25 \mathrm{~m}, 30 \mathrm{~m}, 35 \mathrm{~m}, 40 \mathrm{~m}$ & \\
\hline $\mathrm{C}$ & Ratio between side span and middle span & $0.5,0.6,0.7,0.8,0.9,1.0$ & Changing the side span \\
\hline $\mathrm{D}$ & Number of spans & $3,4,5,6,7$ & \\
\hline $\mathrm{E}$ & Weight of the bridge & $(0.6,0.8,1.0,1.2,1.4) \times \rho$ & Changing the density \\
\hline $\mathrm{F}$ & Stiffness of the bridge & $(0.6,0.8,1.0,1.2,1.4) \times E$ & Changing the modules \\
\hline G & Damping ratio of the bridge & $(0.6,0.8,1.0,1.2,1.4) \times \xi$ & \\
\hline $\mathrm{H}$ & Weight of the vehicle & $(0.6,0.8,1.0,1.2,1.4) \times M_{v}$ & Including body and tyres \\
\hline I & Upper stiffness of the vehicle & $(0.6,0.8,1.0,1.2,1.4) \times k_{s}$ & \\
\hline $\mathrm{J}$ & Upper damping of the vehicle & $(0.6,0.8,1.0,1.2,1.4) \times c_{s}$ & \\
\hline $\mathrm{K}$ & Lower stiffness of the vehicle & $(0.6,0.8,1.0,1.2,1.4) \times k_{t}$ & \\
\hline $\mathrm{L}$ & Lower damping of the vehicle & $(0.6,0.8,1.0,1.2,1.4) \times c_{t}$ & \\
\hline M & Speed of the vehicle & $20 \sim 120 \mathrm{~km} / \mathrm{h}(\mathrm{step}=20 \mathrm{~km} / \mathrm{h})$ & \\
\hline
\end{tabular}

$M_{v}$ : the whole weight of the vehicle, $k_{s}$ : upper stiffness, $c_{s}$ : upper damping, $k_{t}:$ lower stiffness, and $c_{t}:$ lower stiffness. The values of all the parameters are obtained from the fundamental model (Table 7).

half of the length of the middle span. So the span ratio of the side span and the middle span ranges from 0.5 to 1.0 in this study. The effect of span ratio on dynamic responses of the vehicle-bridge system is shown in Figure 6.

It can be seen from Figure 6 that the change of the DLA is almost the same as that of the acceleration of the bridge. In the side span, they slightly decrease and then increase and then keep steady. In the middle span, they firstly go up and then go down. In addition, the vibration acceleration of the vehicle body keeps steady at first, and then it goes down. Moreover, it can be found that all of these dynamic responses reach their extreme value when the span ratio is 0.9 . In China, as for the fabricated girder bridge, the span ratio is equal to 1.0 in common. And, as for the cast in place, the span ratio usually ranges from 0.6 to 0.8 .

To determine the span ratio in design of the bridge, both the static and dynamic characteristics should be paid attention to. 


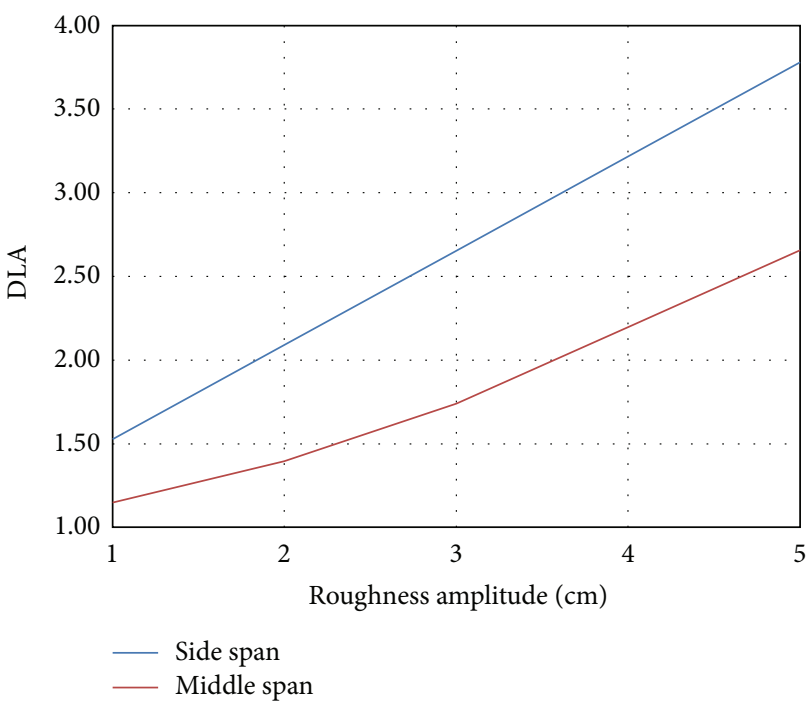

(a) DLA of the bridge

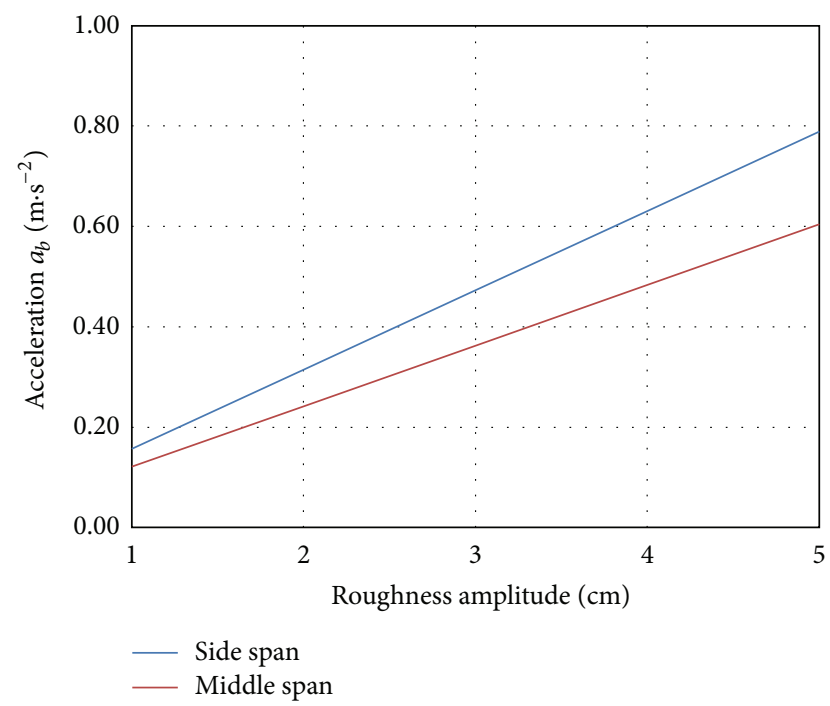

(b) Acceleration of the bridge

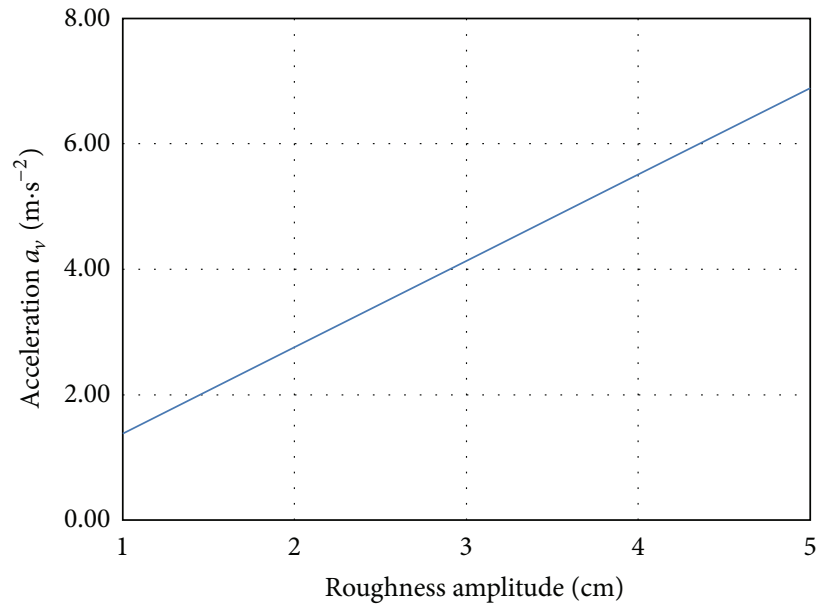

(c) Acceleration of the vehicle

Figure 4: Effect of roughness on dynamic responses of the vehicle-bridge system.

3.4. Effect of Spans Number. For middle- and small-span continuous girder bridges, the number of spans is always ranging from 3 to 7 , owning to the expansion or contraction according to the change of temperature. The effect of spans number on dynamic responses of the vehicle-bridge system is shown in Figure 7.

It can be seen from Figure 7 that the effect of spans number on the DLA of the bridge is not significant, especially for the DLA in the side span. However, the vibration acceleration of the bridge decreases with the increasing of the spans number. Moreover, the change of the vibration acceleration in the side span is much more similar to that in the middle span. Additionally, the vibration acceleration of the vehicle body is little influenced by the spans number of the bridge, as the fundamental natural frequency stays the same for bridges with different number of spans.

Based on the conclusion in this study, the dynamic performance is better for the bridge with more spans. However, the expansion or contraction induced by the change of the temperature may be larger when there are more spans. As a result, it has to be synthetically considered in the design.

3.5. Effect of Bridge Weight. The bridge weight is changed according to amending the density of the material. This method can make sure that the area and the stiffness of the cross-section of the bridge are invariable. The effect of bridge weight on dynamic responses of the vehicle-bridge system is shown in Figure 8.

It can be seen from Figure 8 that as the bridge weight increases, the DLA in the side span keeps steady, while the DLA in the middle span jumpily decreases. However, the change of the vibration acceleration in the side span and that in the middle span are almost the same. They slightly increase and then decrease. Additionally, the vibration acceleration of the vehicle body goes up and down, and the range is small. 


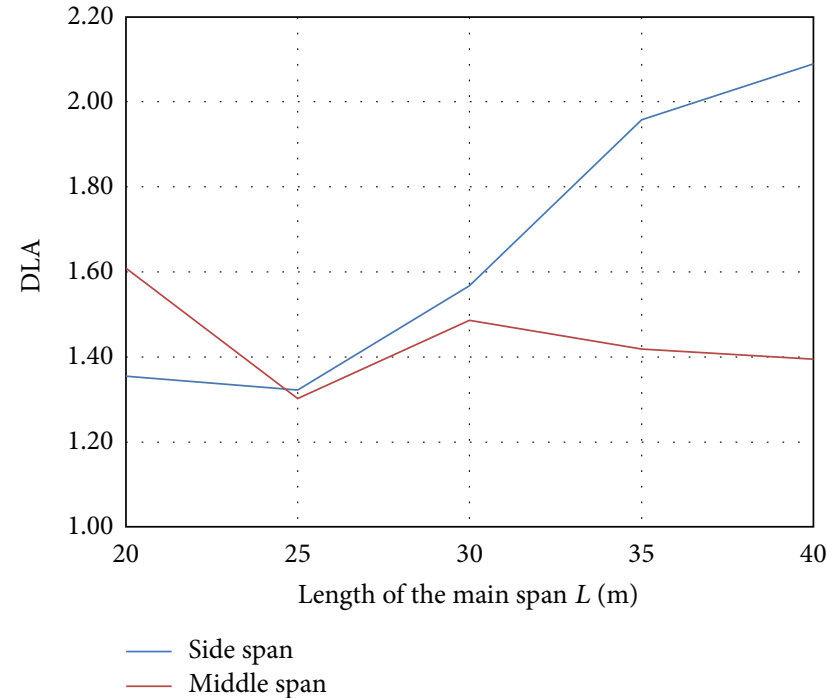

(a) DLA of the bridge

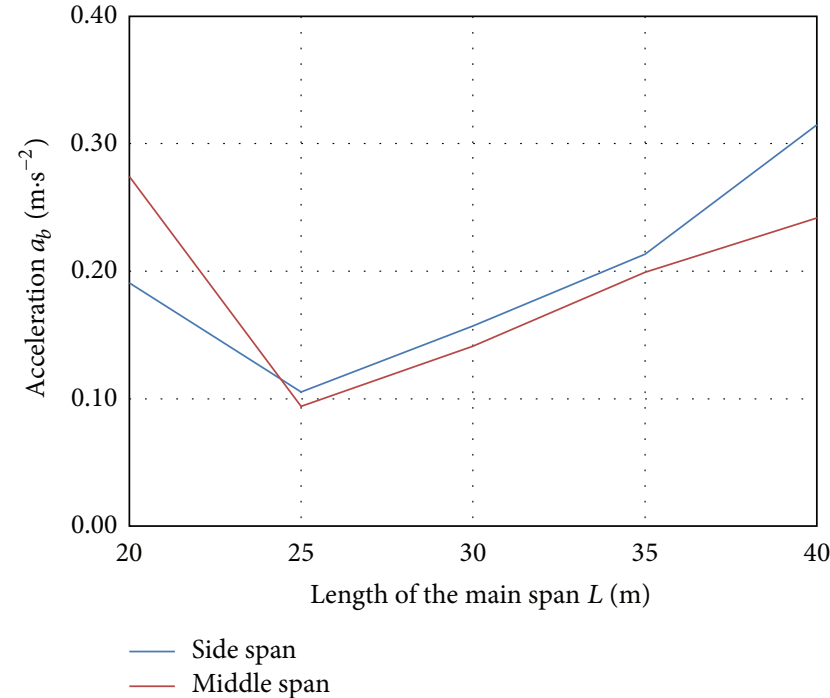

(b) Acceleration of the bridge

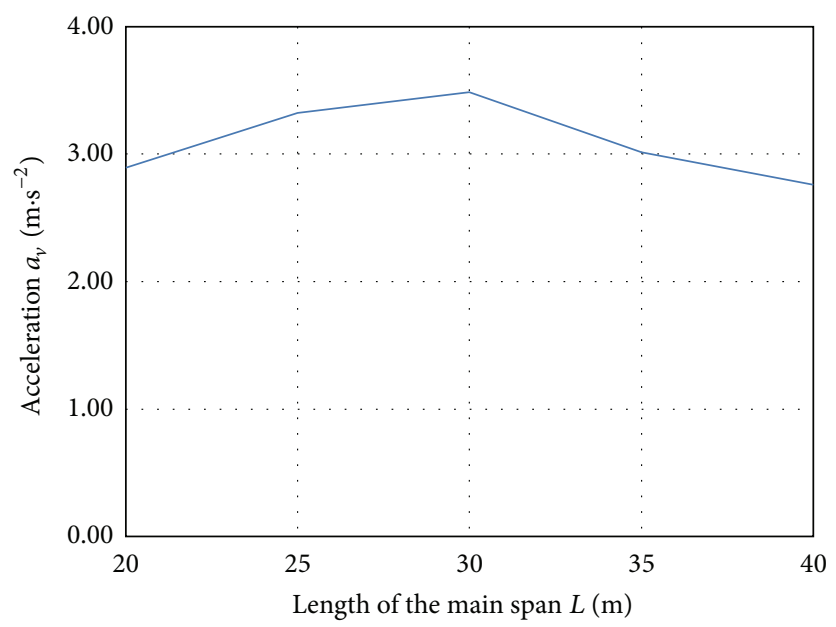

(c) Acceleration of the vehicle

FIGURE 5: Effect of span length on dynamic responses of the vehicle-bridge system.

In natural, it may be related to the dynamic characteristics of the bridge. The natural frequency is lower when the bridge weight is bigger. As for the vehicle-bridge coupled vibration system, the resonance phenomenon will appear when its natural frequencies are so approximate.

3.6. Effect of Bridge Stiffness. The bridge stiffness is changed according to amending the elasticity modules of the material. This method can make sure that the area and the weight of the bridge are invariable. The effect of bridge stiffness on dynamic responses of the vehicle-bridge system is shown in Figure 9.

It can be seen from Figure 9 that, with the increasing of the bridge stiffness, the DLA in the side span continues to rise, while the DLA in the middle span slightly decreases and then increases. However, the change of the vibration acceleration in the side span and that in the middle span are almost the same. They fluctuate and the range is small.
Additionally, the bridge stiffness has little influence on the vibration acceleration of the vehicle body.

Similarly, the natural frequency is higher when the bridge stiffness is bigger. Also, as for the vehicle-bridge coupled vibration system, the resonance phenomenon will appear when its natural frequencies are so approximate.

3.7. Effect of Bridge Damping. As for the concrete structure, the damping ratio is assumed to be 0.05 . In this study, it floats up and down at 40 percent. The effect of bridge damping on dynamic responses of the vehicle-bridge system is shown in Figure 10.

It can be seen from Figure 10 that the damping ratio has little influence on the DLA of the bridge. But the vibration acceleration of the bridge significantly decreases with the increasing of the damping ratio. Similarly, the vibration acceleration of the vehicle body continues to go down as the damping ratio increases. 


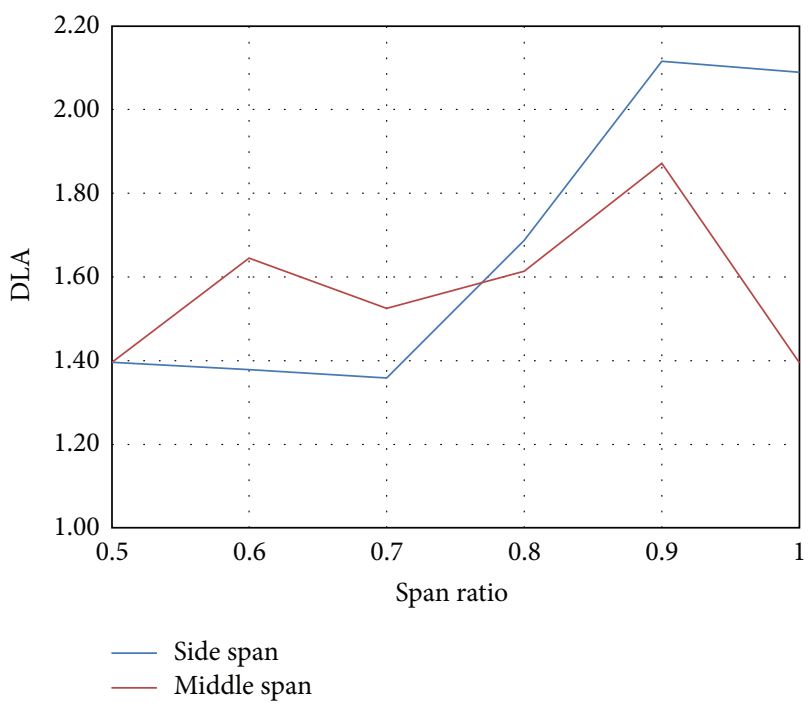

(a) DLA of the bridge

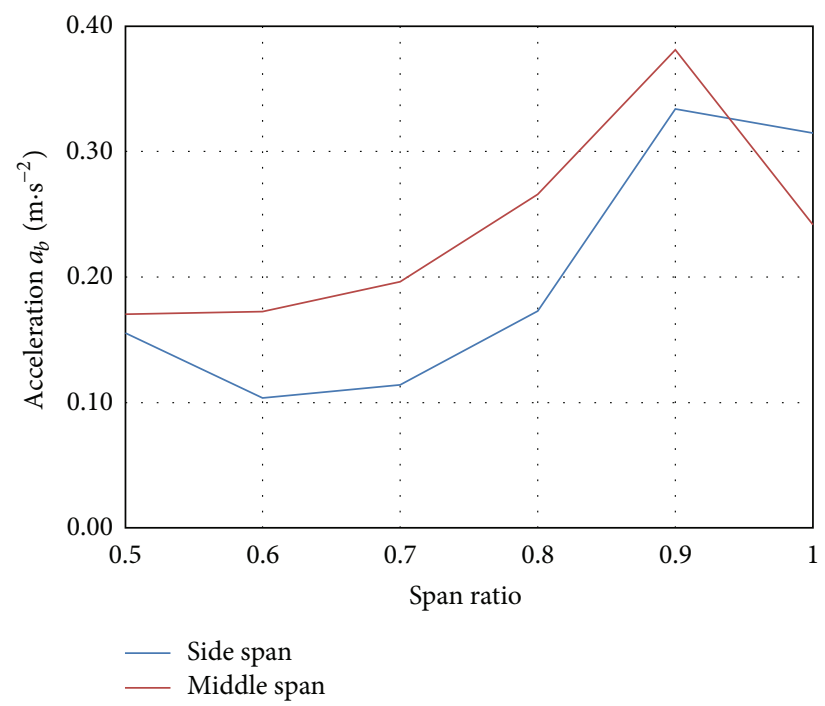

(b) Acceleration of the bridge

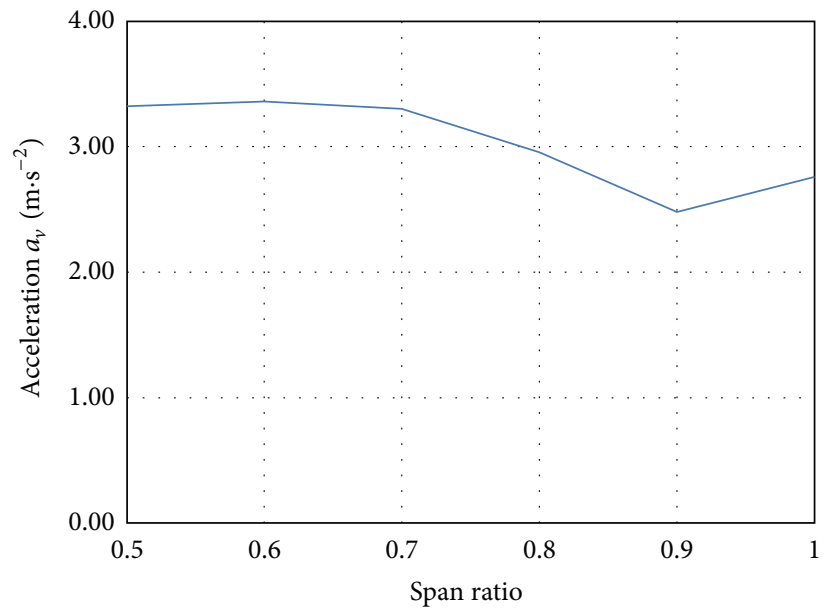

(c) Acceleration of the vehicle

FIgURE 6: Effect of span ratio on dynamic responses of the vehicle-bridge system.

Damping is one of the most important dynamic characteristics of the bridge. Up till now, it cannot be obtained by calculation. The only way to obtain the damping of the structure is by measuring in the fielding test. However, according to the results in this paper, the damping is not so important for calculating the DLA. But it is closely related to the vibration acceleration of the bridge and the vehicle, which may influence the inertia force of the bridge and the riding comfort. Therefore, the damping should still be noticed.

3.8. Effect of Vehicle Weight. To investigate the effect of the vehicle weight on dynamic responses of the bridge, the factor of the vehicle weight is introduced, and the fundamental weight is assumed to be 35 tons. In this study, the factor ranges from 0.6 to 1.4 at the step of 0.2 . The effect of vehicle weight on dynamic responses of the vehicle-bridge system is shown in Figure 11.
It can be seen from Figure 11 that when the factor is smaller than 1.0, the DLA in the side span slightly decreases and then increases, while the DLA in the middle span firstly decreases and then keeps steady. When the factor is bigger than 1.0, the DLA in the side span decreases with the increasing of the vehicle weight, but the DLA in the middle span increases with the increasing of the vehicle weight. However, as the vehicle weight increases, the vibration acceleration in the side span goes down, while that in the middle span goes up. In addition, the vibration acceleration of the vehicle body decreases with the increasing of the vehicle weight.

Obviously, the effect of vehicle weight on dynamic responses in different positions is not the same. Limiting the vehicle weight can effectively reduce the static stress of the bridge, but its influence on the dynamic responses is not clearly enough. In particular, the change of the vibration acceleration in different positions of the bridge is completely the opposite. 


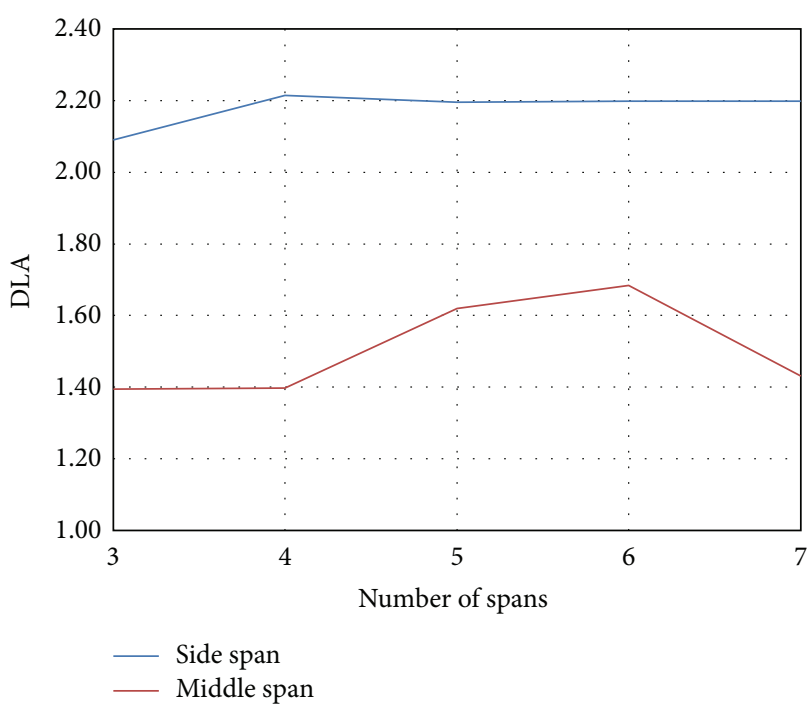

(a) DLA of the bridge

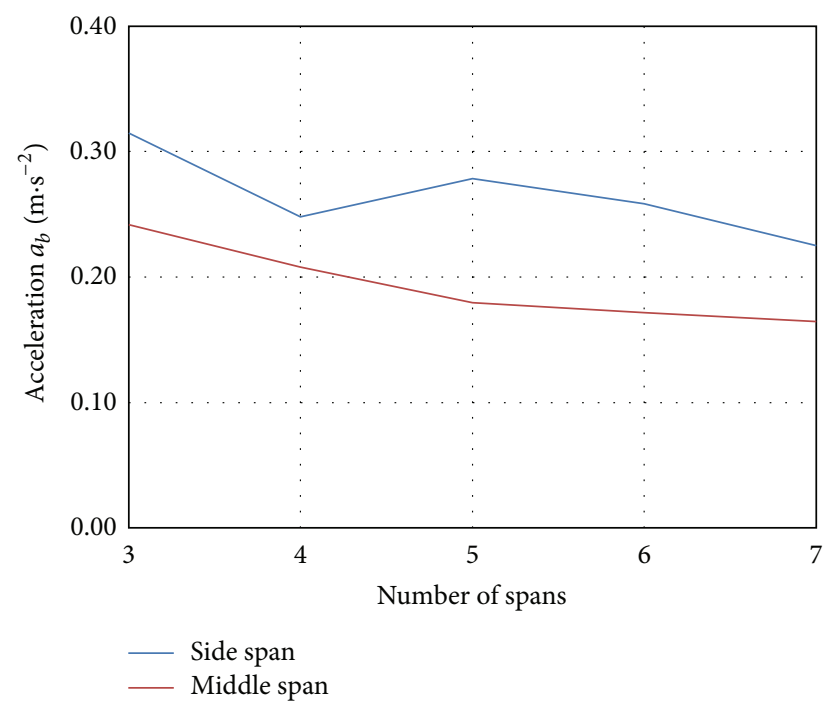

(b) Acceleration of the bridge

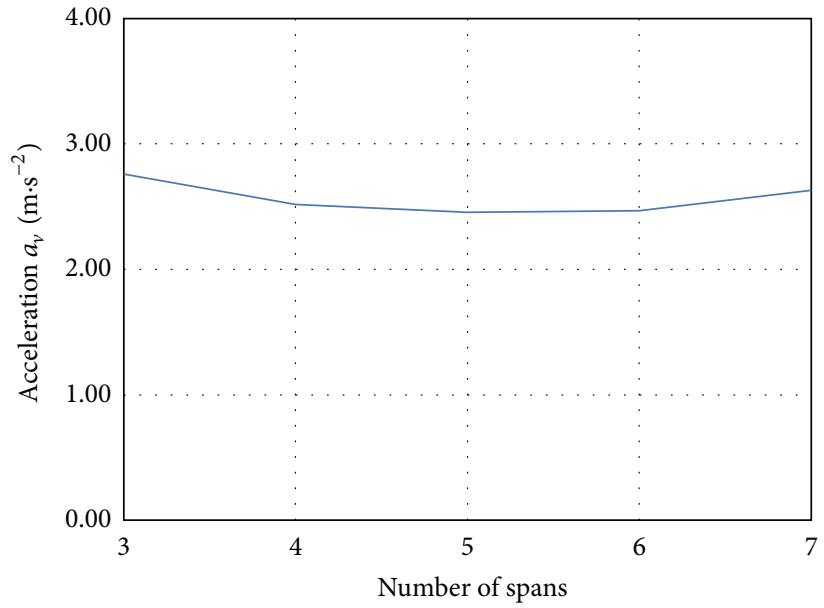

(c) Acceleration of the vehicle

Figure 7: Effect of spans number on dynamic responses of the vehicle-bridge system.

3.9. Effect of Upper Stiffness. To investigate the effect of the upper stiffness on dynamic responses of the vehicle-bridge system, the factor of the upper stiffness is introduced. In this study, the factor ranges from 0.6 to 1.4 at the step of 0.2 . The effect of upper stiffness on dynamic responses of the vehiclebridge system is shown in Figure 12.

It can be seen from Figure 12 that the DLA of the bridge almost goes down with the increasing of the upper stiffness of the vehicle. However, as the upper stiffness of the vehicle increases, the vibration acceleration of the bridge goes up. Moreover, the change of the acceleration in the side span is faster than that in the middle span. In other words, the effect of the upper stiffness on the dynamic response of the side span is much more sensitive. In addition, the vibration acceleration of the vehicle body continues to go up with the increasing of the upper stiffness of the vehicle.

As a result, the upper stiffness of the vehicle not only influences the dynamic responses of the bridge but also significantly affects the vibration acceleration of the vehicle body, which is closely related to the comfort of passengers and the safety of the goods. Therefore, to find the friendly stiffness of the vehicle is urgent and efficient in the area of riding comfort analysis.

3.10. Effect of Upper Damping. To investigate the effect of the upper damping on dynamic responses of the vehicle-bridge system, the factor of the upper damping is introduced. In this study, the factor ranges from 0.6 to 1.4 at the step of 0.2 . The effect of upper damping on dynamic responses of the vehiclebridge system is shown in Figure 13.

It can be seen from Figure 13 that all of the dynamic responses of the vehicle-bridge system decease with the increasing of the upper damping of the vehicle. The change of the DLA in the side span is faster than that in the middle span. However, the change of the vibration acceleration in the side span is almost the same as that in the middle span. It has to be 


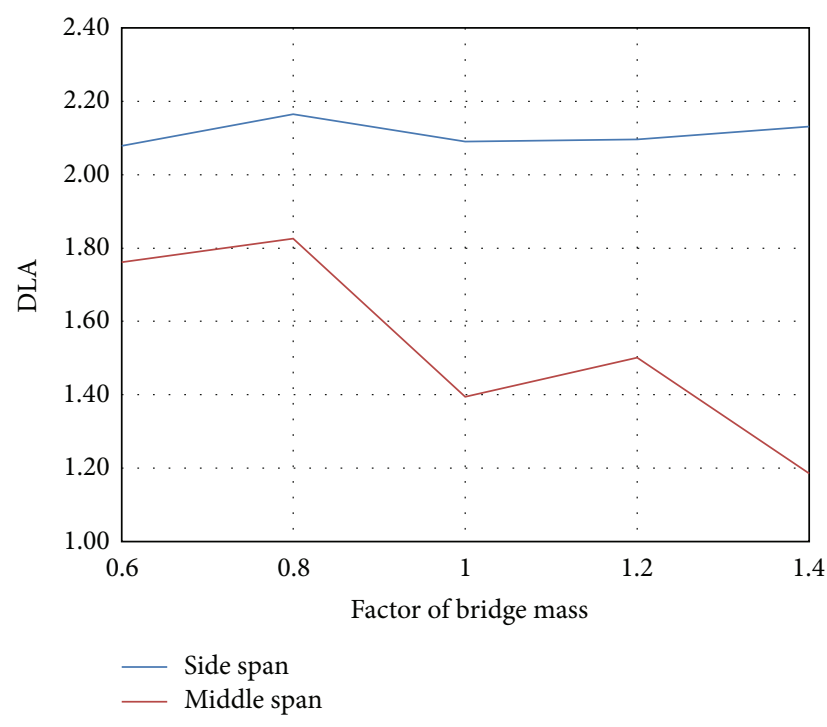

(a) DLA of the bridge

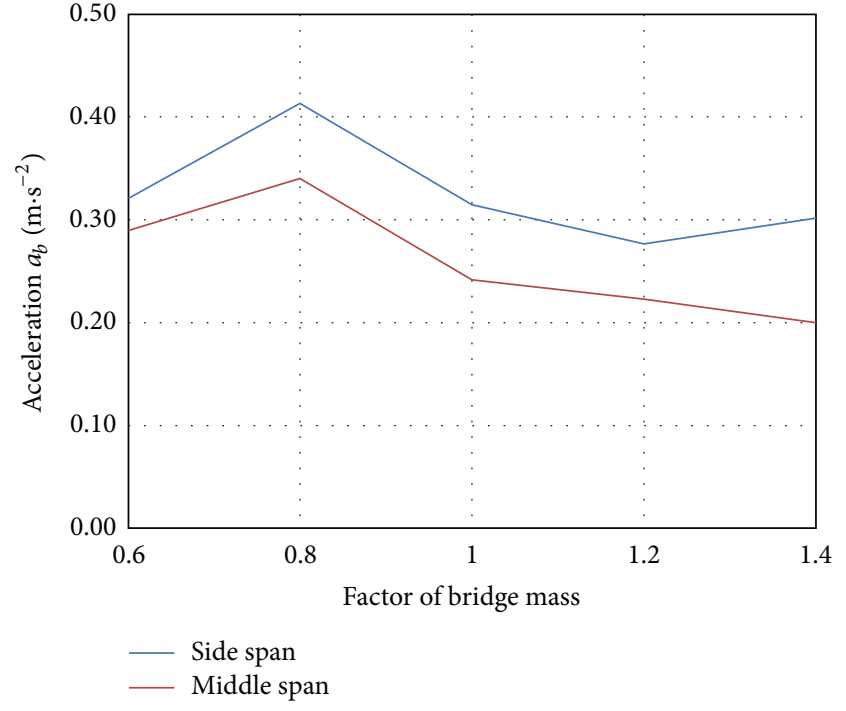

(b) Acceleration of the bridge

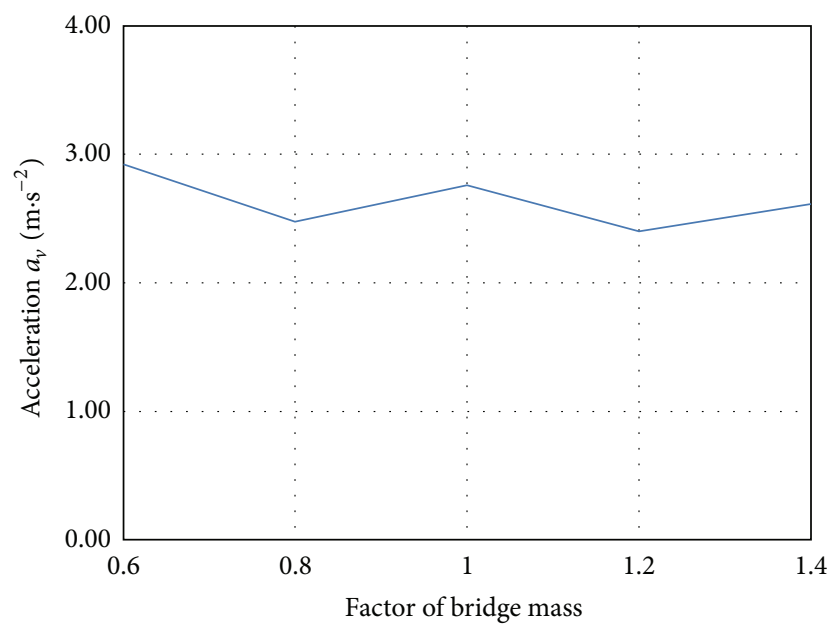

(c) Acceleration of the vehicle

FIGURE 8: Effect of bridge weight on dynamic responses of the vehicle-bridge system.

emphasized that the influence of the upper damping on the vibration acceleration of the vehicle is the most significant. In other words, the shock absorber system of the vehicle is so important in its design.

3.11. Effect of Lower Stiffness. To investigate the effect of the lower stiffness on dynamic responses of the vehicle-bridge system, the factor of the lower stiffness is introduced. In this study, the factor ranges from 0.6 to 1.4 at the step of 0.2 . The effect of lower stiffness on dynamic responses of the vehiclebridge system is shown in Figure 14.

It can be seen from Figure 14 that as the lower stiffness of the vehicle increases, the change of the DLA in the side span and that in the middle span are entirely the opposite. The former one slightly increases and then decreases, while the latter one slightly decreases and then increases. However, the vibration acceleration of the bridge goes up with the increasing of the lower stiffness. Moreover, the change of the vibration acceleration in the side span is faster than that in the middle span. Additionally, the vibration acceleration of the vehicle body goes up firstly and then keeps steady.

Comparing Figure 12 with Figure 14, it can be found that the effect of the upper stiffness is almost the same as the effect of the lower stiffness. Moreover, the former one is more significant than the latter one.

3.12. Effect of Lower Damping. To investigate the effect of the lower damping on dynamic responses of the vehicle-bridge system, the factor of the lower damping is introduced. In this study, the factor ranges from 0.6 to 1.4 at the step of 0.2 . The effect of lower damping on dynamic responses of the vehiclebridge system is shown in Figure 15.

It can be seen from Figure 15 that as the lower damping increases, all of dynamic responses of the vehicle-bridge system are falling. But the changing range of them is small. 


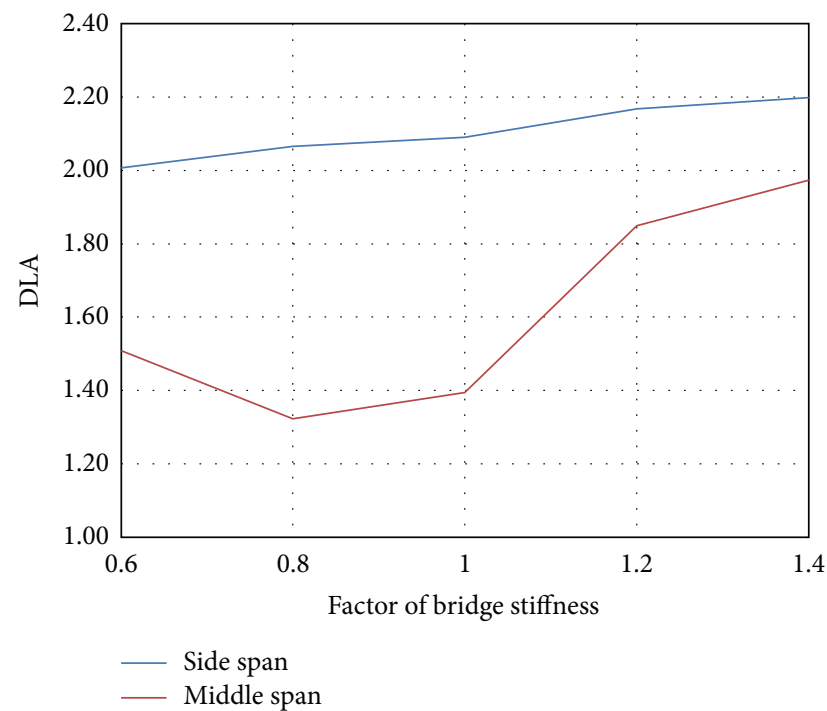

(a) DLA of the bridge

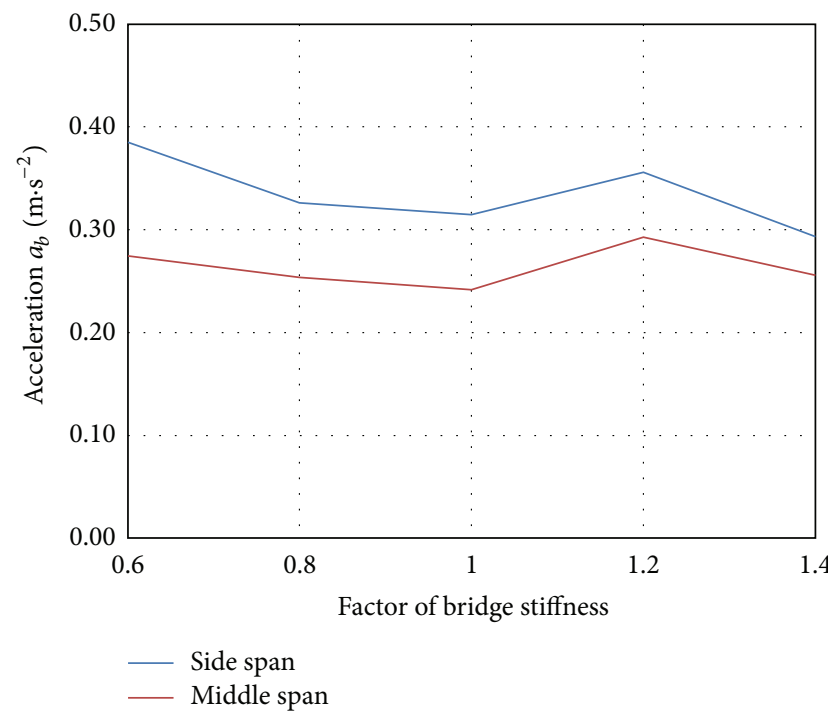

(b) Acceleration of the bridge

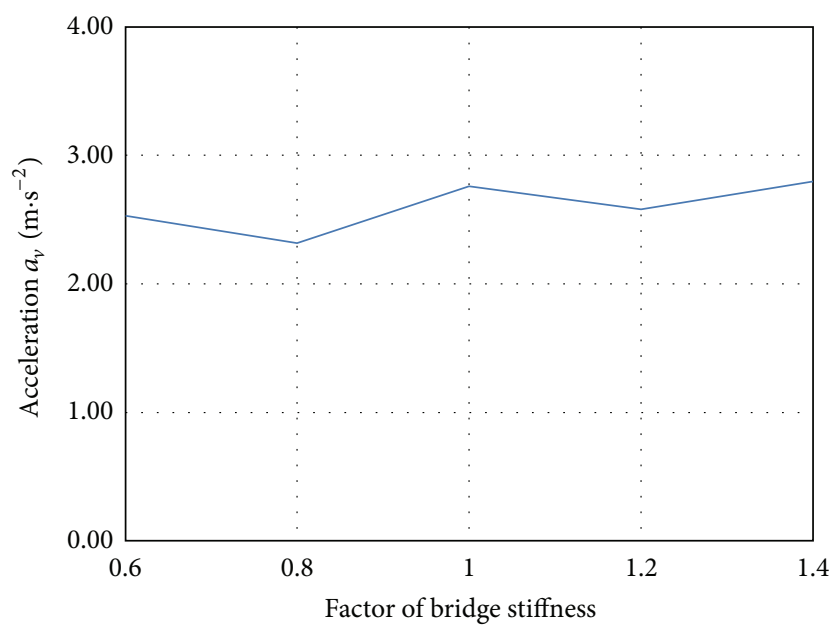

(c) Acceleration of the vehicle

Figure 9: Effect of bridge stiffness on dynamic responses of the vehicle-bridge system.

Also, the dynamic responses in the side span are significantly larger than those in the middle span, especially for the DLA.

Comparing Figure 13 with Figure 15, it can be found that the effect of the upper damping is almost the same as the effect of the lower damping. Moreover, the former one is more significant than the latter one.

3.13. Effect of Vehicle Speed. As for the loading truck, the speed ranges from $20 \mathrm{~km} / \mathrm{h}$ to $120 \mathrm{~km} / \mathrm{h}$ at the step of $20 \mathrm{~km} / \mathrm{h}$. The effect of vehicle speed on dynamic responses of the vehicle-bridge system is shown in Figure 16.

It can be seen from Figure 16 that as the speed increases, both the DLA in the side span and the DLA in the middle span increase firstly and then decrease. But the critical speeds of them are not the same, and the former one is bigger than the latter one. However, the vibration acceleration of the bridge goes up with the increasing of the vehicle speed. Similarly, the vibration acceleration of the vehicle body also increases.
Therefore, it has to be noted that limiting the speed directly is not a rational way to ensure the safety of the bridge, which is the common way during the maintenance of the old or damaged bridge.

Obviously, the effect of every parameter on the dynamic responses of the vehicle-bridge system can be studied by the program VBCVA. When one parameter is studied, the other parameters should be fixed. But, according to this method, the results may not occasionally be the same as the actual condition, because the interaction effects among different parameters are not considered.

\section{Numerical Simulations Based on the Orthogonal Experimental Design}

There are two ways for the analysis of factors influencing the dynamic responses of the vehicle-bridge coupled vibration system, full factorial designs and fractional factorial designs. 


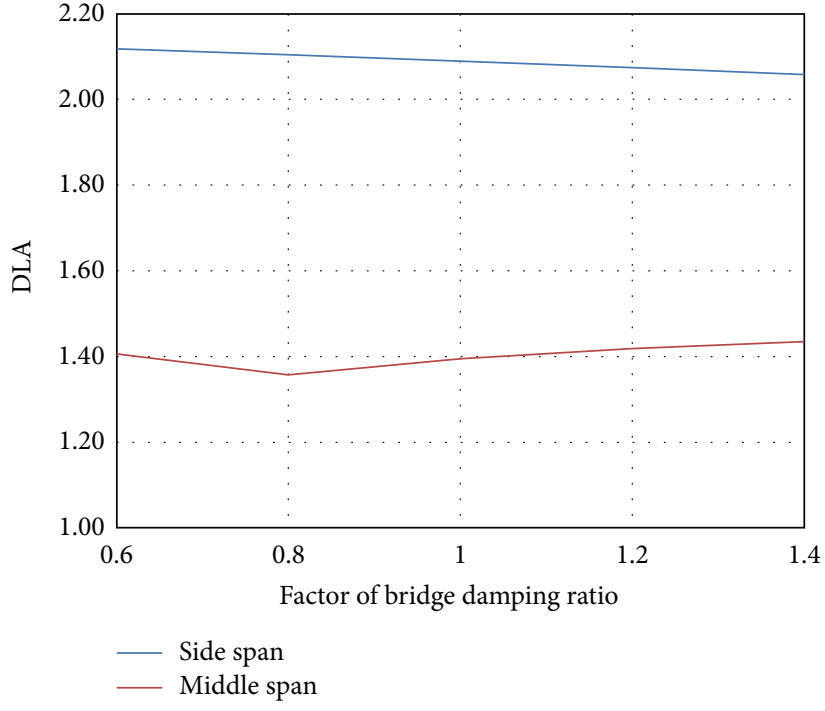

(a) DLA of the bridge

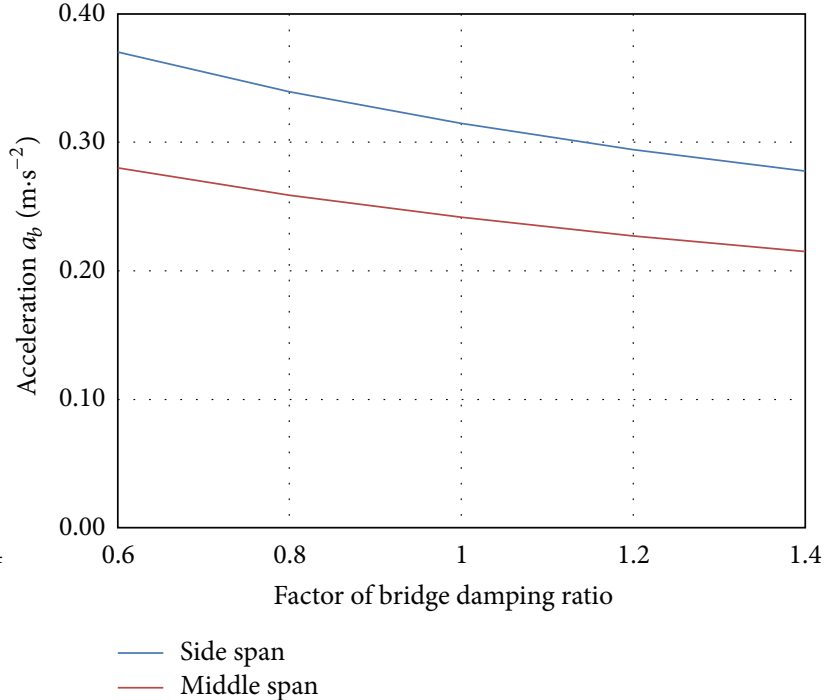

(b) Acceleration of the bridge

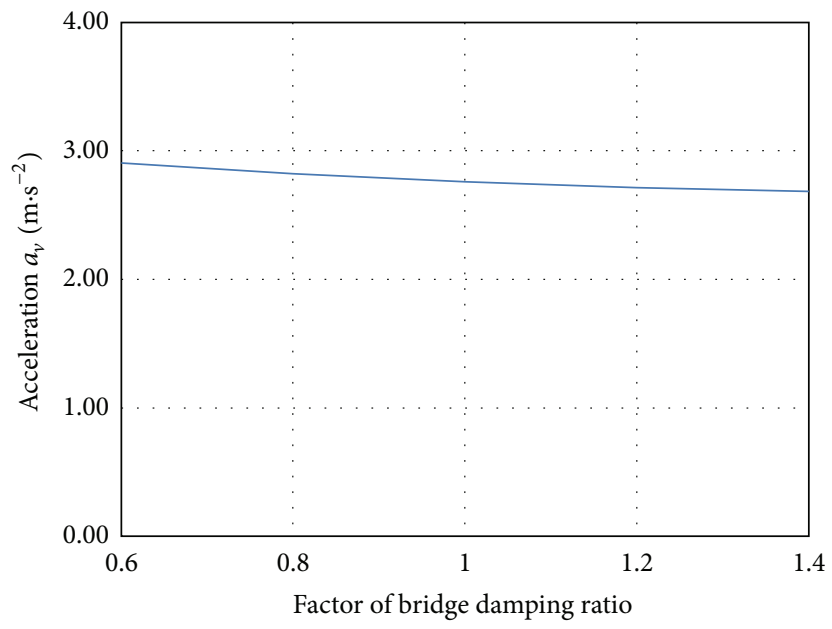

(c) Acceleration of the vehicle

FIGURE 10: Effect of bridge damping on dynamic responses of the vehicle-bridge system.

Full factorial designs reveal whether the effect of each factor depends on the levels of other factors in the experiment. This is the primary reason for multifactor experiments. One factorial experiment can show "interaction effects" that a series of experiments each involving a single factor cannot [42]. However, fractional factorial designs permit investigation of the effects of many factors in fewer runs than a full factorial design.

Data from fractional factorial designs are interpreted based on the following two assumptions. The first one is the sparsity of important effects. Only a few of the many possible effects are prominent. Even if many effects are nonzero, we expect a few to stand out as much larger than the rest. The other one is the simplicity of important effects. Main effects and/or two-factor interactions are more likely to be important than high-order interactions. This is also known as the hierarchical ordering principle.
Therefore, considering the high efficiency, the orthogonal experimental design, one common type of the fractional factorial design, is adopted in this study, including the numerical simulation without interaction and the numerical simulation with interaction.

4.1. Orthogonal Experimental Design. According to the orthogonal experimental design, two objectives can be attained. The first objective is to select fewer typical combinations for the test. And the other objective is to obtain the correct conclusions by the scientific method based on the limited combinations. The orthogonal experimental design consists of the design of test plan and the process of test data.

As for the design of test plan, the main procedures are listed as follows [43]. Firstly, the objective and the test index are clearly proposed. Secondly, the factors and their levels are 


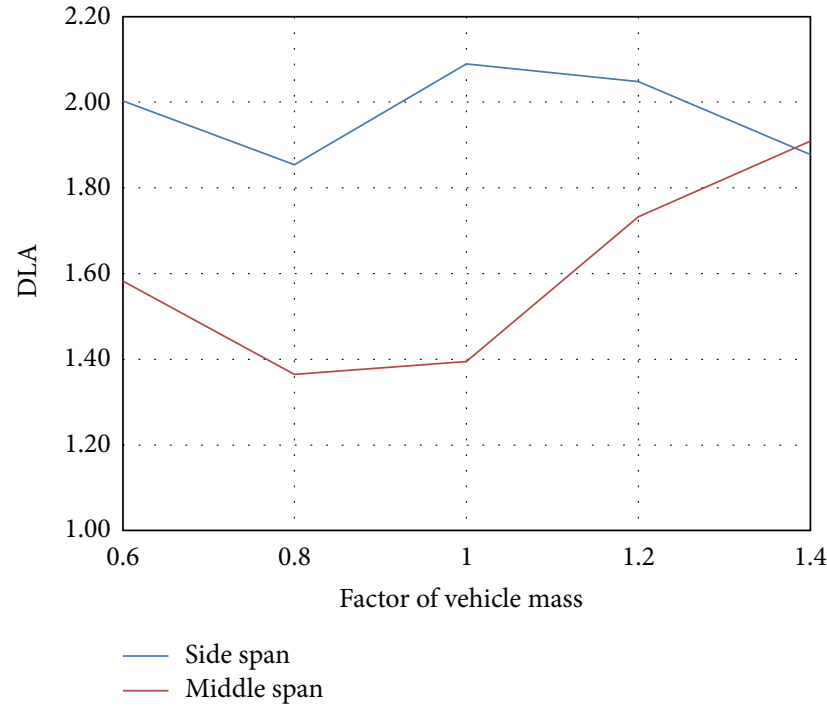

(a) DLA of the bridge

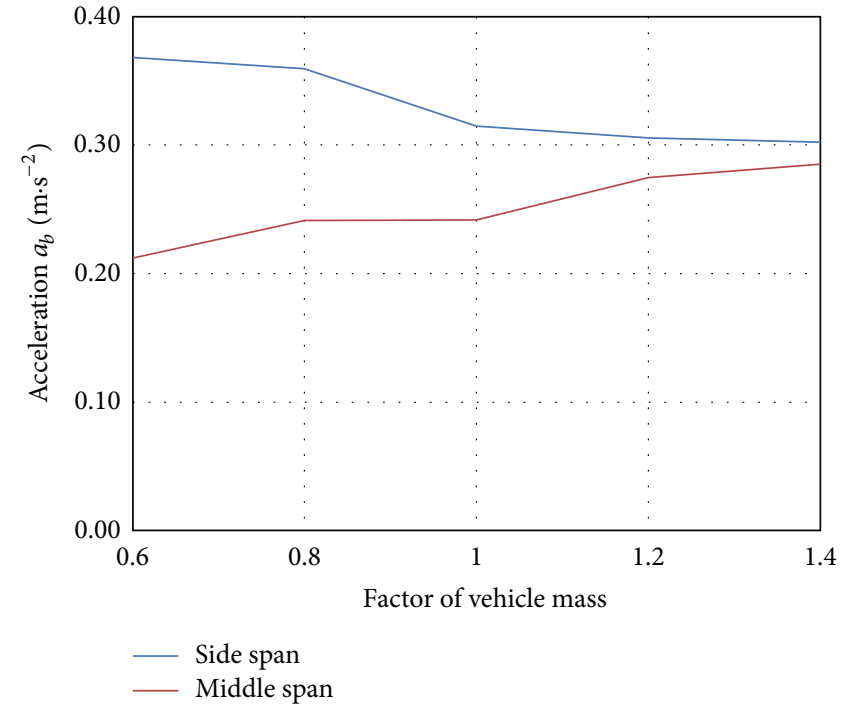

(b) Acceleration of the bridge

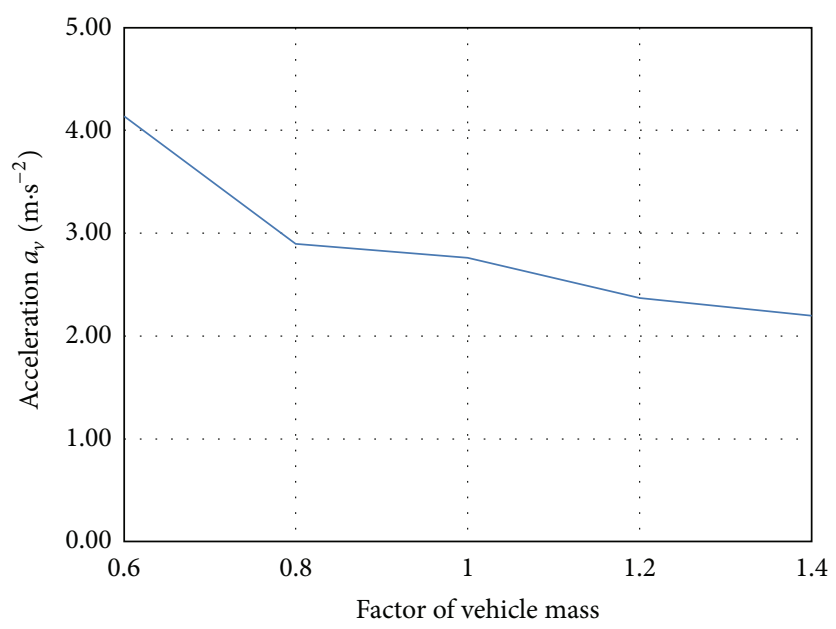

(c) Acceleration of the vehicle

FIGURE 11: Effect of vehicle weight on dynamic responses of the vehicle-bridge system.

determined based on the comprehension in this research field other than the knowledge of statistics. Thirdly, the rational orthogonal table is selected, including the table considering interaction and the table without interaction. Fourthly, the table header is designed. Finally, the test plan is formed.

As for the process of the test data, two methods are adopted, including the range analysis and the variance analysis [44]. The range analysis is much simpler and more convenient. However, the test error cannot be estimated, and the reliability of the results cannot be determined. Also, it cannot be applied in the fields of regression analysis and regression design. But the variance analysis can remedy the defects above.

The method of range analysis is also called the visual analysis method and the $R$ (the abbreviation of the range) method. It consists of two procedures, calculation and judgment. The diagram can be seen in Figure 17.
In Figure 17 the $K_{j m}$ is the sum of the test index with the $m$ th level in the $j$ th column and $k_{j m}$ is the average of the $K_{j m}$. In addition, the $R_{j}$ is the difference between the maximum and the minimum value of the $k_{j m}$ :

$$
R_{j}=\max \left(k_{j 1}, k_{j 2}, \ldots, k_{j m}\right)-\min \left(k_{j 1}, k_{j 2}, \ldots, k_{j m}\right) .
$$

The $R_{j}$ is represented for the changing amplitude of the test index with the changing of the levels of the $j$ th factor. Therefore, it can be concluded that the influence of the $j$ th factor on the test index is much more significant if the value of $R_{j}$ is bigger. Sometimes, for more clarity, the trend plot is given.

Variance analysis is more rigorous. There are four steps to realize the variance analysis $[45,46]$. 


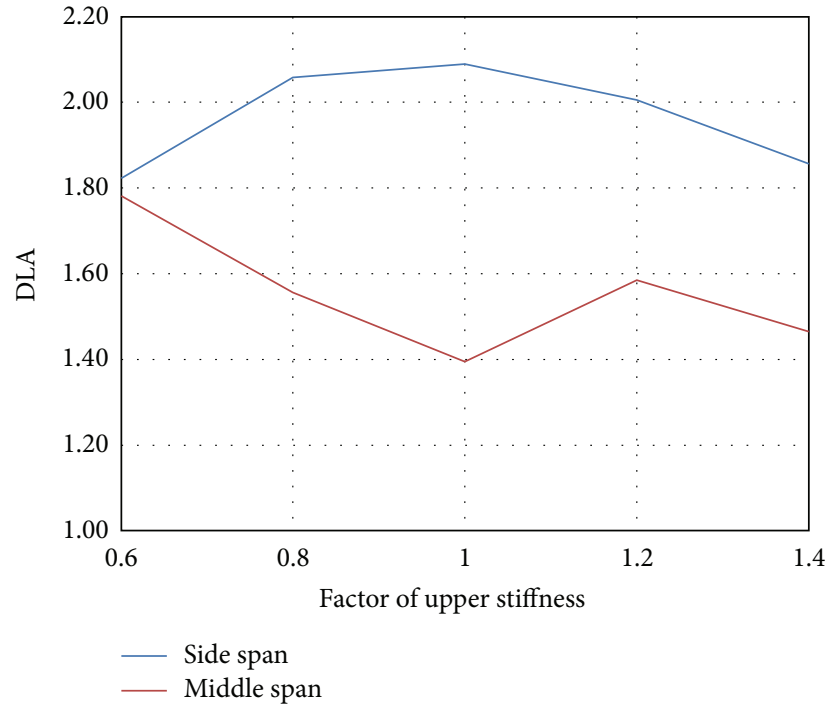

(a) DLA of the bridge

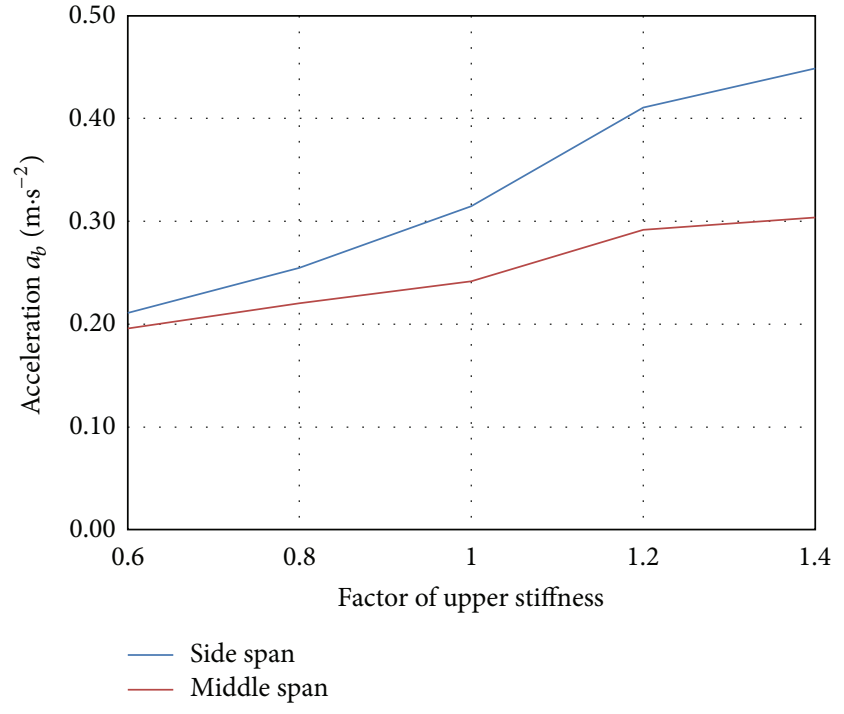

(b) Acceleration of the bridge

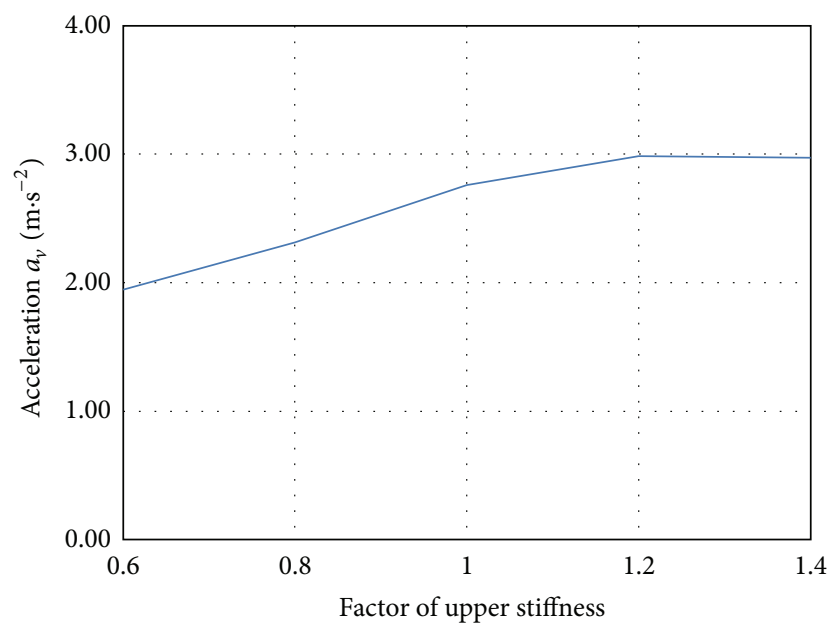

(c) Acceleration of the vehicle

FIGURE 12: Effect of upper stiffness on dynamic responses of the vehicle-bridge system.

Step 1. As for every factor, calculate the sum of square of deviations $\left(S_{j}\right)$, the degree of freedom (dof, $f_{j}$ ), and the variance estimation $\left(\sigma_{j}\right)$.

Step 2. Estimate the variance of the error $\left(\sigma_{e}\right)$.

Step 3. Obtain the test static $F$ and compare $F$ with its critical value $F_{\alpha}$ for given significance level $\alpha$.

Step 4. For simplicity, the variance analysis table is listed, including the process and the results. Consider

$$
\begin{gathered}
S=\sum_{i=1}^{a}\left(y_{i}-\bar{y}\right)^{2}=\sum_{i=1}^{a} y_{i}^{2}-\frac{1}{a}\left(\sum_{i=1}^{a} y_{i}\right)^{2}, \\
S_{j}=\frac{a}{b} \sum_{k=1}^{b}\left(\bar{y}_{j k}-\bar{y}\right)^{2}=\frac{a}{b} \sum_{k=1}^{b} y_{j k}^{2}-\frac{1}{a}\left(\sum_{i=1}^{a} y_{i}\right)^{2},
\end{gathered}
$$

$$
F_{j}=\frac{\sigma_{j}}{\sigma_{e}}=\frac{S_{j} / f_{j}}{S_{e} / f_{e}}
$$

in which $y_{i}$ is the index result of the $i$ th run and $y_{j k}$ is the index result of the $j$ th factor with the $k$ th level. Also, $S_{e}$ and $f_{e}$ denote, respectively, the sum of square of deviations and the degree of freedom of the error. It has to be noted that the error has resulted from all of the vacant columns in the orthogonal array. Also, the accuracy increases with the increasing dof of the error [47]. Therefore, if the significance level of one factor is larger than 0.25 , it can be included as the error.

In this study, the orthogonal table $L_{27}\left(3^{13}\right)$ is used for the numerical simulation without interaction, while the orthogonal table $L_{16}\left(2^{15}\right)$ is used for the numerical simulation with interaction. 


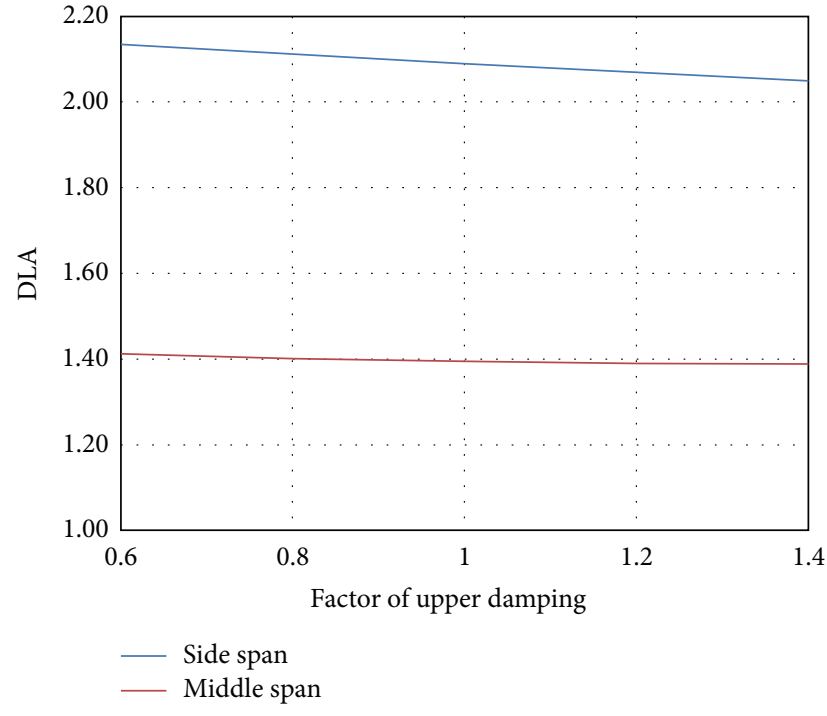

(a) DLA of the bridge

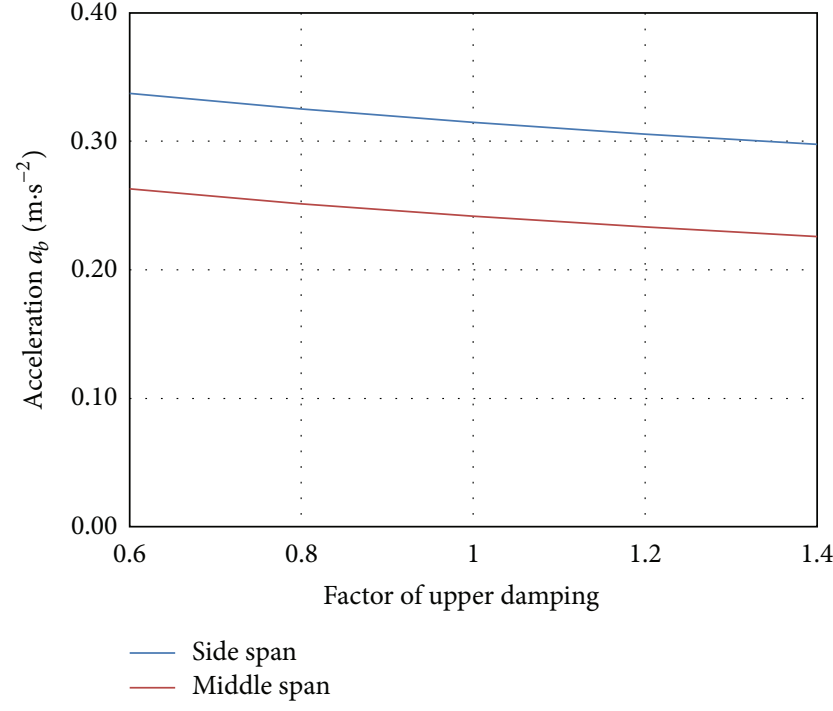

(b) Acceleration of the bridge

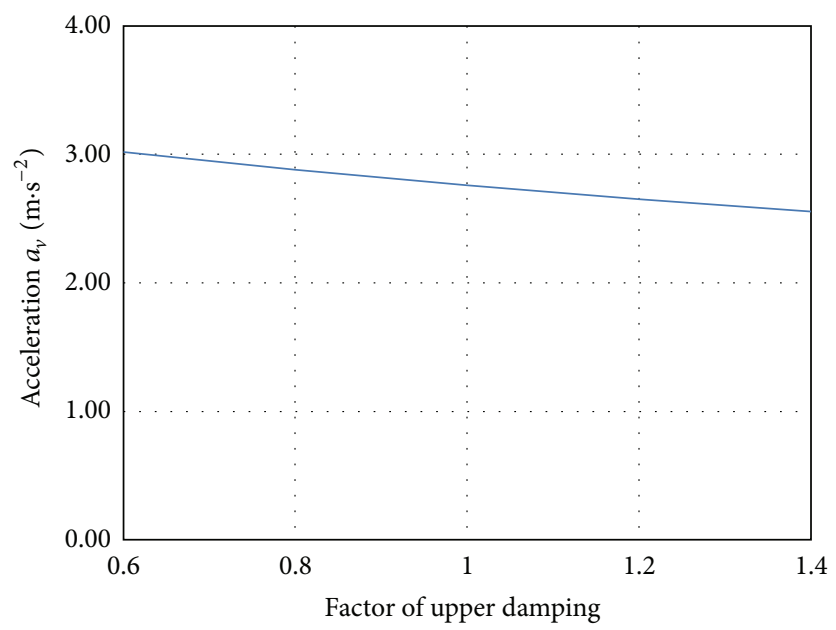

(c) Acceleration of the vehicle

FIGURE 13: Effect of upper damping on dynamic responses of the vehicle-bridge system.

4.2. Numerical Simulation without Interaction. There are thirteen factors possibly affecting dynamic responses of the vehicle-bridge coupled vibration system. A large number of studies [8] have proved that the roughness is the most significant factor. Therefore, the roughness is not arranged in the orthogonal table. The other twelve factors are arranged in the orthogonal table, once in a column. And the residual column is thought as the test error.

The results obtained from the VBCVA are listed in Table 9. The range analysis of the data can be seen in Table 10 and Figure 18. The variance analysis of the data is shown in Table 11 .

It can be concluded that the influence of factors on different indices is listed as follows.

(i) For DLA in the side span of the bridge, consider

$\mathrm{B}>\mathrm{H}>\mathrm{C}>\mathrm{J}>\mathrm{D}>\mathrm{E}>\mathrm{K}>\mathrm{F}>\mathrm{I}>\mathrm{L}>\mathrm{G}>\mathrm{M}$. (ii) For DLA in the middle span of the bridge, consider

$\mathrm{D}>\mathrm{C}>\mathrm{E}>\mathrm{H}>\mathrm{I}>\mathrm{G}>\mathrm{B}>\mathrm{K}>\mathrm{L}>\mathrm{M}>\mathrm{J}>\mathrm{F}$.

(iii) For vibration acceleration in the side span of the bridge, consider

$\mathrm{D}>\mathrm{B}>\mathrm{E}>\mathrm{J}>\mathrm{M}>\mathrm{I}>\mathrm{C}>\mathrm{F}>\mathrm{K}>\mathrm{G}>\mathrm{L}>\mathrm{H}$.

(iv) For vibration acceleration in the middle span of the bridge, consider

$\mathrm{D}>\mathrm{B}>\mathrm{C}>\mathrm{E}>\mathrm{J}>\mathrm{M}>\mathrm{I}>\mathrm{H}>\mathrm{G}>\mathrm{F}>\mathrm{L}>\mathrm{K}$.

(v) For vibration acceleration of the vehicle body, consider

$\mathrm{H}>\mathrm{I}>\mathrm{K}>\mathrm{B}>\mathrm{C}>\mathrm{J}>\mathrm{D}>\mathrm{L}>\mathrm{F}>\mathrm{E}>\mathrm{G}>\mathrm{M}$. 


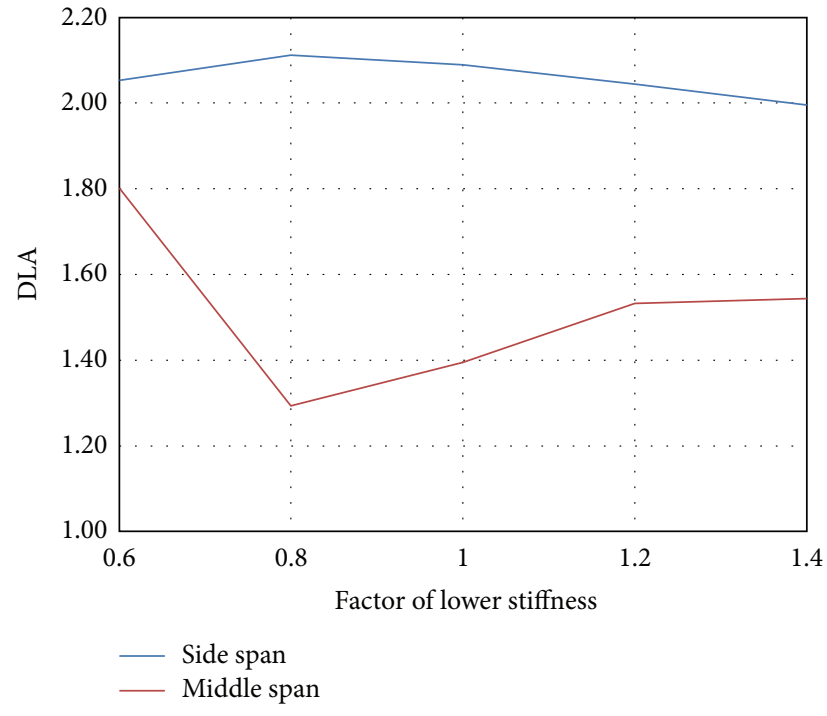

(a) DLA of the bridge

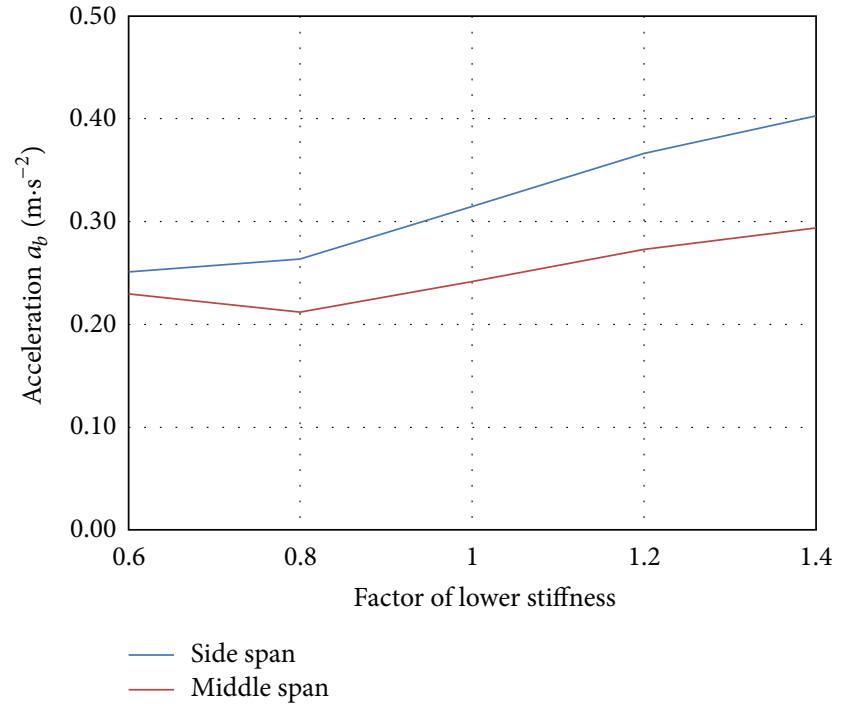

(b) Acceleration of the bridge

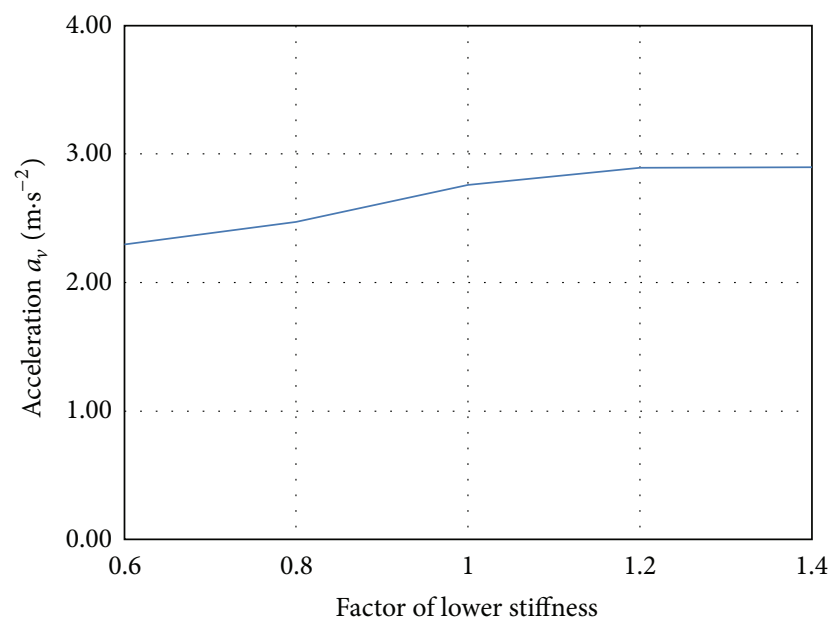

(c) Acceleration of the vehicle

FIGURE 14: Effect of lower stiffness on dynamic responses of the vehicle-bridge system.

It has to be noted that the roughness is assumed as the significant factor. Obviously, among other factors, the most important factors affecting the different dynamic responses are not the same.

4.3. Numerical Simulation with Interaction. As mentioned earlier, the interaction almost exists in all of physical phenomena. When the interaction is so small, it can be ignored in application. However, as for research, we do not know whether the interaction can be ignored or not at first.

Based on the results from the above section, eight most important factors influencing the DLA are selected, and some interactions between them are investigated. They are the pavement roughness (A), the length of the main span (B), the ratio between the side span and the middle span $(C)$, the number of spans (D), the weight of the bridge (E), the weight of the vehicle $(\mathrm{H})$, the upper stiffness of the vehicle (I), and the upper damping of the vehicle (J). Meanwhile, due to the calculation cost and the existing orthogonal array, the number of levels is determined as two for each factor. To avoid the mixture, the most important factor is arranged at first. It can be seen in Table 12 .

The results obtained from the VBCVA are listed in Table 13. The range analysis of the data can be seen in Table 14. The variance analysis of the data is shown in Table 15.

It can be concluded that the influence of factors on different indices is listed as follows.

(i) For DLA in the side span of the bridge, consider

$$
\begin{aligned}
\mathrm{A} & >\mathrm{I}>\mathrm{B} \times \mathrm{C}>\mathrm{D}>\mathrm{J}>\mathrm{H}>\mathrm{D} \times \mathrm{C}>\mathrm{E}>\mathrm{A} \times \mathrm{D} \\
& >\mathrm{B}>\mathrm{A} \times \mathrm{C}>\mathrm{A} \times \mathrm{B}>\mathrm{D} \times \mathrm{B}>\mathrm{C} .
\end{aligned}
$$

(ii) For DLA in the middle span of the bridge, consider

$$
\begin{gathered}
\mathrm{B}>\mathrm{A}>\mathrm{D}>\mathrm{D} \times \mathrm{B}>\mathrm{A} \times \mathrm{B}>\mathrm{H}>\mathrm{E}>\mathrm{A} \times \mathrm{D} \\
>\mathrm{J}>\mathrm{B} \times \mathrm{C}>\mathrm{I}>\mathrm{D} \times \mathrm{C}>\mathrm{C}>\mathrm{A} \times \mathrm{C} .
\end{gathered}
$$




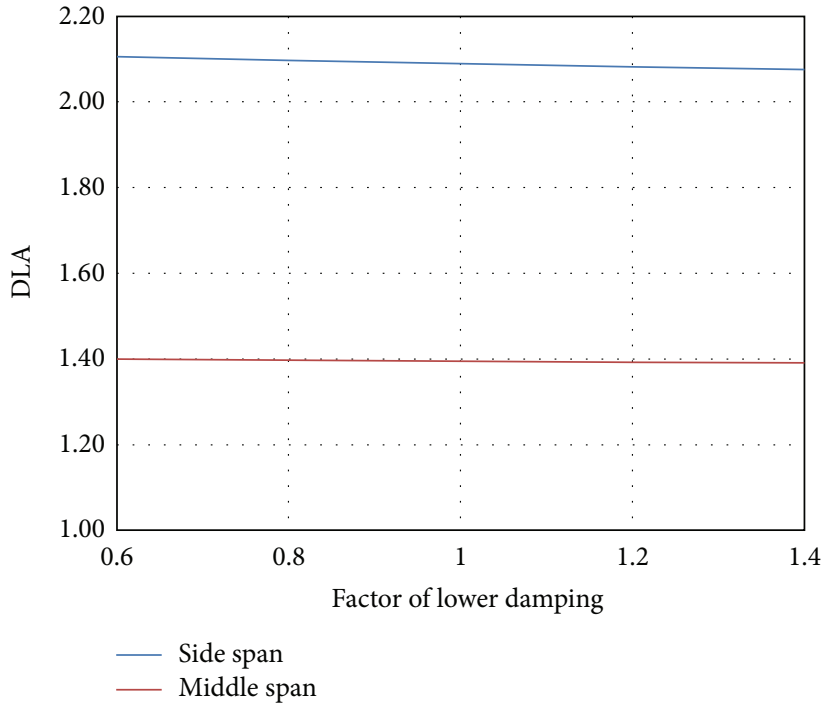

(a) DLA of the bridge

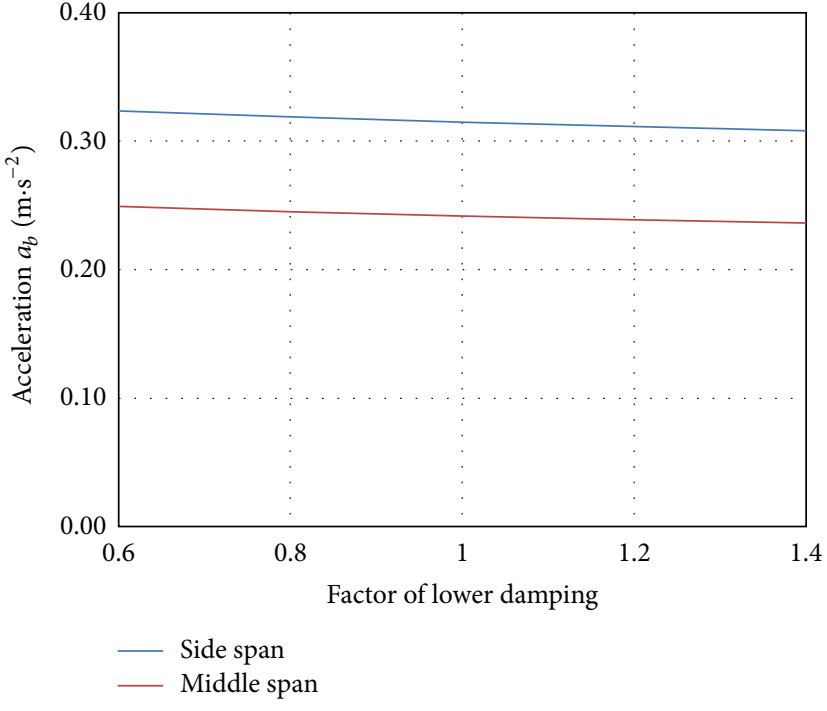

(b) Acceleration of the bridge

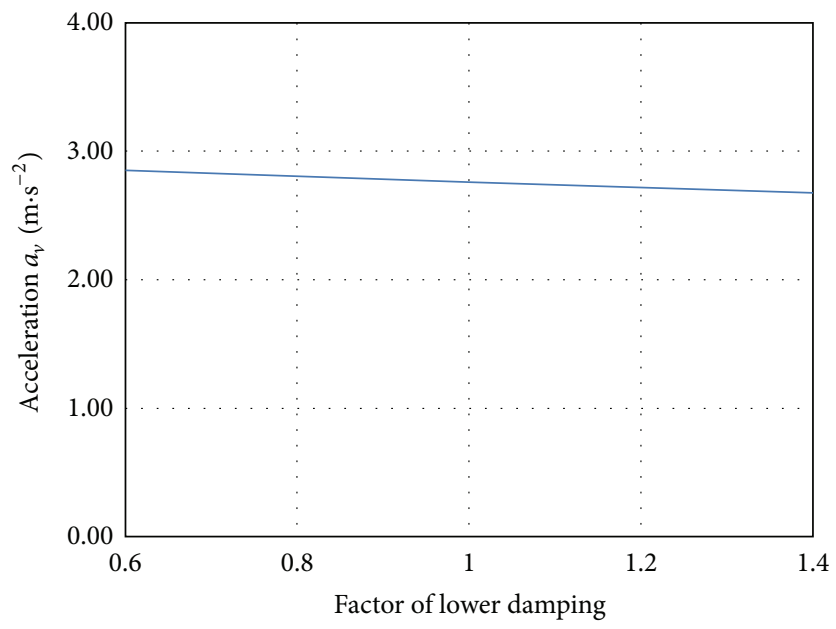

(c) Acceleration of the vehicle

FIGURE 15: Effect of lower damping on dynamic responses of the vehicle-bridge system.

(iii) For vibration acceleration in the side span of the bridge, consider

$$
\begin{gathered}
\mathrm{B} \times \mathrm{C}>\mathrm{A}>\mathrm{D}>\mathrm{C}>\mathrm{I}>\mathrm{J}>\mathrm{B}>\mathrm{E}>\mathrm{A} \times \mathrm{D} \\
>\mathrm{A} \times \mathrm{B}>\mathrm{D} \times \mathrm{C}>\mathrm{A} \times \mathrm{C}>\mathrm{D} \times \mathrm{B}>\mathrm{H} .
\end{gathered}
$$

(iv) For vibration acceleration in the middle span of the bridge, consider

$$
\begin{gathered}
\mathrm{A}>\mathrm{B}>\mathrm{A} \times \mathrm{B}>\mathrm{B} \times \mathrm{C}>\mathrm{I}>\mathrm{H}>\mathrm{D}>\mathrm{D} \times \mathrm{B} \\
>\mathrm{A} \times \mathrm{D}>\mathrm{J}>\mathrm{E}>\mathrm{A} \times \mathrm{C}>\mathrm{D} \times \mathrm{C}>\mathrm{C} .
\end{gathered}
$$

(v) For vibration acceleration of the vehicle body, consider

$$
\begin{gathered}
\mathrm{A}>\mathrm{I}>\mathrm{H}>\mathrm{B}>\mathrm{D} \times \mathrm{C}>\mathrm{D} \times \mathrm{B}>\mathrm{J}>\mathrm{A} \times \mathrm{B} \\
>\mathrm{B} \times \mathrm{C}>\mathrm{A} \times \mathrm{D}>\mathrm{D}>\mathrm{A} \times \mathrm{C}>\mathrm{E}>\mathrm{C} .
\end{gathered}
$$

Similarly, for different indices, the most important factors are not the same. Also, it should be noted that some interactions are not ignored.

4.4. Comparison with the Current Code. In the current code of China (General Code for Design of Highway Bridges and Culverts) [48], the dynamic load allowance $(\mu)$ is defined as the function of the natural frequency. It is given by

$$
\mu= \begin{cases}0.05 & f<1.5 \mathrm{~Hz} \\ 0.1767 \ln f-0.0157 & 1.5 \mathrm{~Hz} \leq f \leq 14 \mathrm{~Hz} \\ 0.45 & f>14 \mathrm{~Hz}\end{cases}
$$

where $f$ is the fundamental natural frequency of the bridge. Its unit is $\mathrm{Hz}$. 


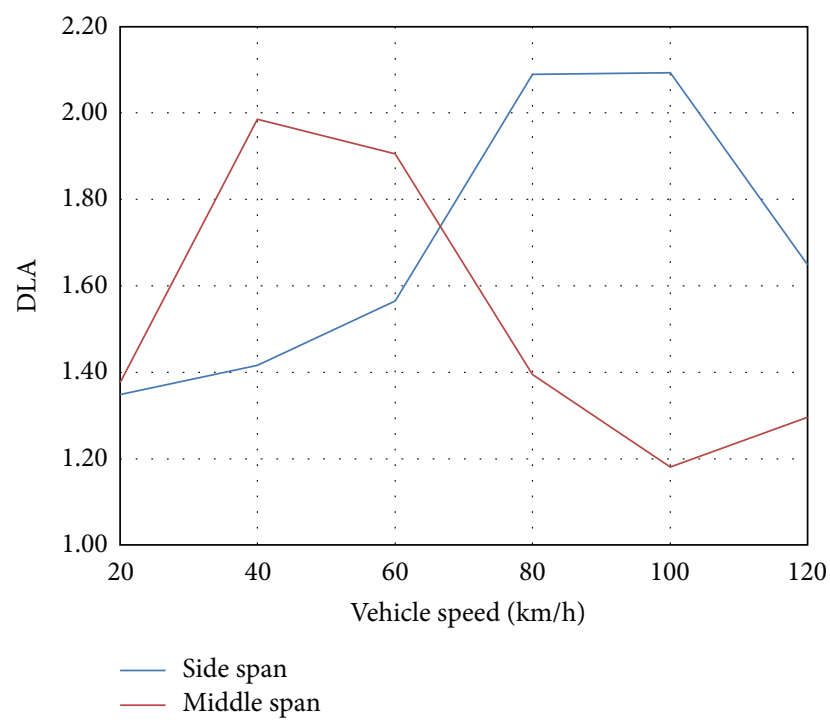

(a) DLA of the bridge

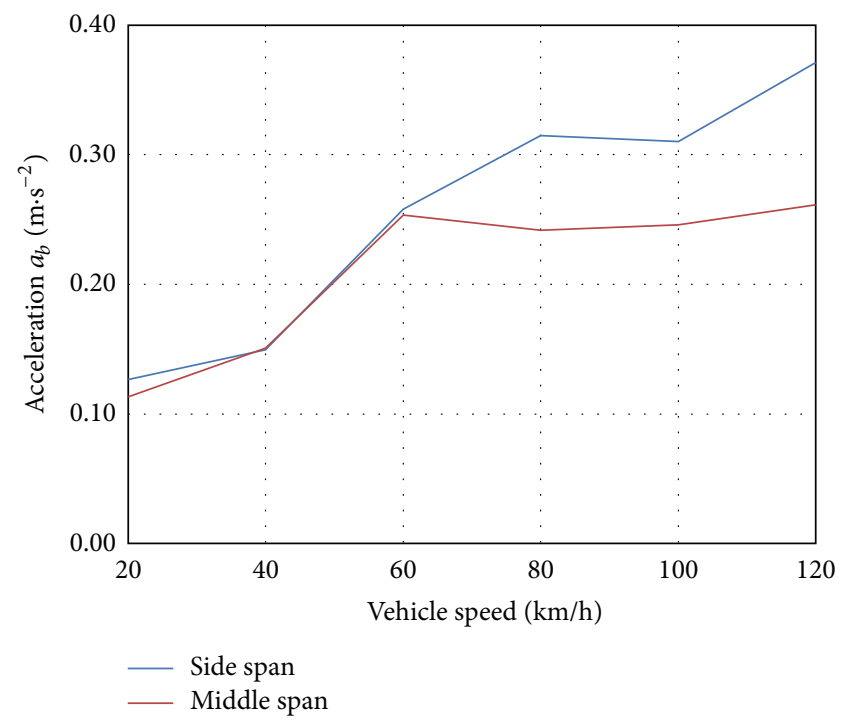

(b) Acceleration of the bridge

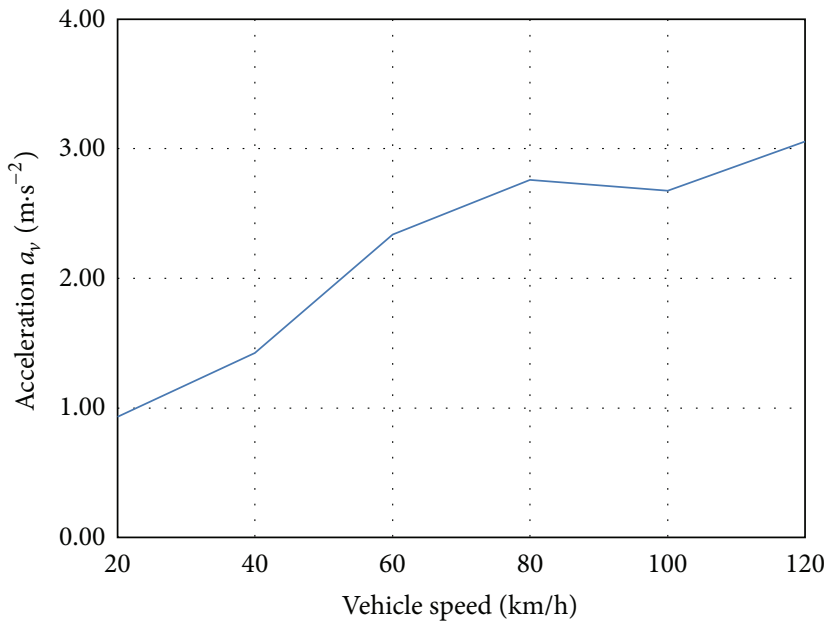

(c) Acceleration of the vehicle

FIGURE 16: Effect of vehicle speeds on dynamic responses of the vehicle-bridge system.

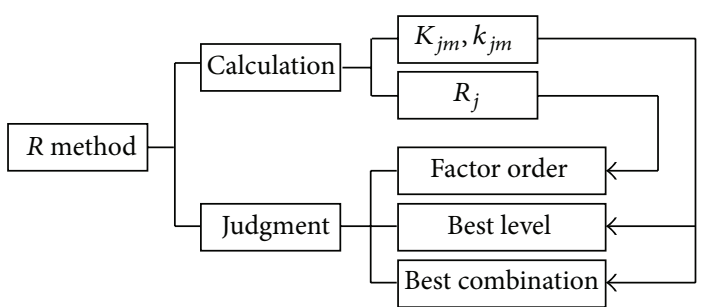

FIgURE 17: The diagram of the $R$ method.

The DLA calculated by the program VBCVA is compared with the DLA obtained based on the current code in China. The results are shown in Figure 19.

It can be seen from Figure 19 that the differences between them are large, especially for the cases of the frequency from
$2 \mathrm{~Hz}$ to $4 \mathrm{~Hz}$. It may be related to the natural frequency of the vehicle. In other words, the dynamic load allowance defined in the current code may be not rational enough. To better consider the dynamic effects induced by moving vehicles in the design phase, some revisions may be needed in the future. 
TABLE 9: Results of numerical simulation without interaction.

\begin{tabular}{|c|c|c|c|c|c|c|}
\hline Run & $f_{1}(\mathrm{~Hz})$ & $\mathrm{DLA}_{s}$ & DLA $_{m}$ & $a_{b s}\left(\mathrm{~m} / \mathrm{s}^{2}\right)$ & $a_{b m}\left(\mathrm{~m} / \mathrm{s}^{2}\right)$ & $a_{v}\left(\mathrm{~m} / \mathrm{s}^{2}\right)$ \\
\hline 1 & 14.82 & 1.431 & 2.436 & 0.2499 & 0.7623 & 3.4869 \\
\hline 2 & 16.57 & 1.156 & 2.574 & 0.3564 & 1.1550 & 2.9201 \\
\hline 3 & 18.16 & 1.275 & 2.317 & 0.2758 & 0.8258 & 3.0941 \\
\hline 4 & 8.85 & 1.302 & 1.107 & 0.3288 & 0.2249 & 4.1458 \\
\hline 5 & 9.90 & 1.523 & 1.775 & 0.1865 & 0.1588 & 4.8916 \\
\hline 6 & 10.84 & 1.287 & 1.283 & 0.2236 & 0.1858 & 2.6550 \\
\hline 7 & 5.31 & 1.772 & 1.600 & 0.0899 & 0.1211 & 3.9578 \\
\hline 8 & 5.94 & 1.175 & 1.045 & 0.1257 & 0.1683 & 3.0282 \\
\hline 9 & 6.50 & 1.429 & 1.515 & 0.1237 & 0.1288 & 2.3746 \\
\hline 10 & 4.21 & 1.218 & 1.751 & 0.2646 & 0.1737 & 2.7197 \\
\hline 11 & 4.70 & 1.489 & 2.152 & 0.1145 & 0.1109 & 3.7590 \\
\hline 12 & 5.15 & 1.719 & 1.661 & 0.1441 & 0.0963 & 4.5308 \\
\hline 13 & 4.60 & 1.326 & 1.380 & 0.0784 & 0.1045 & 2.1844 \\
\hline 14 & 5.14 & 1.685 & 1.699 & 0.1005 & 0.1617 & 4.4917 \\
\hline 15 & 5.63 & 1.323 & 1.329 & 0.1537 & 0.1436 & 2.7863 \\
\hline 16 & 4.01 & 1.434 & 1.520 & 0.2780 & 0.1964 & 2.5608 \\
\hline 17 & 4.49 & 1.491 & 1.815 & 0.1407 & 0.1176 & 3.6745 \\
\hline 18 & 4.91 & 1.412 & 1.264 & 0.1521 & 0.1462 & 2.6360 \\
\hline 19 & 2.42 & 1.293 & 1.190 & 0.0866 & 0.2490 & 2.5880 \\
\hline 20 & 2.71 & 1.413 & 1.649 & 0.1057 & 0.2816 & 2.7028 \\
\hline 21 & 2.96 & 1.522 & 2.226 & 0.0794 & 0.3196 & 3.0362 \\
\hline 22 & 2.61 & 1.979 & 1.949 & 0.3605 & 0.4664 & 3.6195 \\
\hline 23 & 2.92 & 1.319 & 2.116 & 0.3079 & 0.4740 & 2.9401 \\
\hline 24 & 3.20 & 1.886 & 2.257 & 0.1505 & 0.2254 & 2.8719 \\
\hline 25 & 2.53 & 1.818 & 1.965 & 0.4168 & 0.2730 & 2.1650 \\
\hline 26 & 2.82 & 1.904 & 1.214 & 0.2497 & 0.2277 & 2.0962 \\
\hline 27 & 3.09 & 2.981 & 2.232 & 0.5926 & 0.3882 & 3.7986 \\
\hline
\end{tabular}

TABLE 10: Range analysis of numerical simulation without interaction.

\begin{tabular}{lcccccccccccc}
\hline Index & $\mathrm{B}$ & $\mathrm{C}$ & $\mathrm{D}$ & $\mathrm{E}$ & $\mathrm{F}$ & $\mathrm{G}$ & $\mathrm{H}$ & $\mathrm{I}$ & $\mathrm{J}$ & $\mathrm{K}$ & $\mathrm{L}$ & $\mathrm{M}$ \\
\hline $\mathrm{DLA}_{s}$ & 0.418 & 0.322 & 0.256 & 0.247 & 0.187 & 0.070 & 0.328 & 0.164 & 0.281 & 0.244 & 0.079 & 0.049 \\
$\mathrm{DLA}_{m}$ & 0.248 & 0.421 & 0.513 & 0.369 & 0.132 & 0.265 & 0.309 & 0.284 & 0.139 & 0.187 & 0.179 & 0.161 \\
$a_{b s}\left(\mathrm{~m} / \mathrm{s}^{2}\right)$ & 0.103 & 0.055 & 0.175 & 0.099 & 0.052 & 0.037 & 0.015 & 0.063 & 0.088 & 0.047 & 0.031 & 0.074 \\
$a_{b m}\left(\mathrm{~m} / \mathrm{s}^{2}\right)$ & 0.276 & 0.245 & 0.299 & 0.240 & 0.044 & 0.046 & 0.047 & 0.084 & 0.093 & 0.015 & 0.016 & 0.090 \\
$a_{v}\left(\mathrm{~m} / \mathrm{s}^{2}\right)$ & 0.526 & 0.477 & 0.401 & 0.309 & 0.342 & 0.141 & 1.099 & 0.640 & 0.457 & 0.595 & 0.394 & 0.083 \\
\hline
\end{tabular}

\section{Conclusions}

In this study, the natural frequencies of the simply supported girder bridge and the continuous girder bridge with uniform cross-section are firstly investigated based on the theoretical derivation and the numerical simulation. And then the effects of different parameters on the dynamic responses of the vehicle-bridge coupled vibration system are discussed by our own program VBCVA. Finally, the orthogonal experimental design method is proposed for the dynamic responses analysis, including the case without interaction and the case considering interaction. The conclusions obtained in this study are summarized as follows.

(1) The empirical formulas on natural frequency of the single-span bridge with different boundary conditions are obtained based on the theoretical derivation. It can be used for the simply supported girder bridge, especially for some old bridges, where bearing and 
TABLE 11: Various analysis of numerical simulation without interaction.

(a) Dynamic load allowance in the side span (DLA $)$

\begin{tabular}{|c|c|c|c|c|c|c|c|c|}
\hline \multirow{2}{*}{ Factor } & \multirow{2}{*}{$S_{j}$} & \multirow{2}{*}{ dof } & \multicolumn{3}{|c|}{ Initial } & \multicolumn{3}{|c|}{ Modification } \\
\hline & & & $\sigma_{j}$ & $F$ & $\alpha$ & $\sigma_{j}$ & $F$ & $\alpha$ \\
\hline $\mathrm{B}$ & 0.8830 & 2 & 0.4415 & 11.01 & 0.10 & 0.4415 & 9.95 & 0.01 \\
\hline $\mathrm{C}$ & 0.4764 & 2 & 0.2382 & 5.94 & 0.25 & 0.2382 & 5.37 & 0.05 \\
\hline $\mathrm{D}$ & 0.3311 & 2 & 0.1656 & 4.13 & 0.25 & 0.1656 & 3.73 & 0.10 \\
\hline $\mathrm{E}$ & 0.2776 & 2 & 0.1388 & 3.46 & 0.25 & 0.1388 & 3.13 & 0.10 \\
\hline $\mathrm{F}$ & 0.1697 & 2 & 0.0848 & 2.12 & $>0.25$ & - & - & \\
\hline G & 0.0237 & 2 & 0.0119 & 0.30 & $>0.25$ & - & - & \\
\hline $\mathrm{H}$ & 0.5193 & 2 & 0.2596 & 6.48 & 0.25 & 0.2596 & 5.85 & 0.05 \\
\hline I & 0.1290 & 2 & 0.0645 & 1.61 & $>0.25$ & - & - & \\
\hline $\mathrm{J}$ & 0.3551 & 2 & 0.1775 & 4.43 & 0.25 & 0.1775 & 4.00 & 0.05 \\
\hline $\mathrm{K}$ & 0.2684 & 2 & 0.1342 & 3.35 & 0.25 & 0.1342 & 3.02 & 0.10 \\
\hline $\mathrm{L}$ & 0.0327 & 2 & 0.0163 & 0.41 & $>0.25$ & - & - & \\
\hline M & 0.0121 & 2 & 0.0060 & 0.15 & $>0.25$ & - & - & \\
\hline Error & 0.0802 & 2 & 0.0401 & & & 0.0444 & & \\
\hline Sum & 3.5581 & 26 & & & & & & \\
\hline
\end{tabular}

(b) Dynamic load allowance in the middle span (DLA $)$

\begin{tabular}{|c|c|c|c|c|c|c|c|c|}
\hline \multirow{2}{*}{ Factor } & \multirow{2}{*}{$S_{j}$} & \multirow{2}{*}{ dof } & \multicolumn{3}{|c|}{ Initial } & \multicolumn{3}{|c|}{ Modification } \\
\hline & & & $\sigma_{j}$ & $F$ & $\alpha$ & $\sigma_{j}$ & $F$ & $\alpha$ \\
\hline B & 0.2762 & 2 & 0.1381 & 4.07 & 0.25 & 0.1381 & 2.36 & 0.25 \\
\hline $\mathrm{C}$ & 0.8983 & 2 & 0.4492 & 13.23 & 0.10 & 0.4492 & 7.67 & 0.01 \\
\hline $\mathrm{D}$ & 1.2312 & 2 & 0.6156 & 18.13 & 0.10 & 0.6156 & 10.52 & 0.01 \\
\hline $\mathrm{E}$ & 0.6344 & 2 & 0.3172 & 9.34 & 0.10 & 0.3172 & 5.42 & 0.05 \\
\hline $\mathrm{F}$ & 0.1002 & 2 & 0.0501 & 1.48 & $>0.25$ & - & - & \\
\hline G & 0.3232 & 2 & 0.1616 & 4.76 & 0.25 & 0.1616 & 2.76 & 0.25 \\
\hline $\mathrm{H}$ & 0.5709 & 2 & 0.2855 & 8.41 & 0.25 & 0.2855 & 4.88 & 0.05 \\
\hline I & 0.3674 & 2 & 0.1837 & 5.41 & 0.25 & 0.1837 & 3.14 & 0.10 \\
\hline $\mathrm{J}$ & 0.0934 & 2 & 0.0467 & 1.38 & $>0.25$ & - & - & \\
\hline $\mathrm{K}$ & 0.1627 & 2 & 0.0814 & 2.40 & $>0.25$ & - & - & \\
\hline $\mathrm{L}$ & 0.1598 & 2 & 0.0799 & 2.35 & $>0.25$ & - & - & \\
\hline M & 0.1183 & 2 & 0.0592 & 1.74 & $>0.25$ & - & - & \\
\hline Error & 0.0679 & 2 & 0.0340 & & & 0.0585 & & \\
\hline Sum & 5.0039 & 26 & & & & & & \\
\hline
\end{tabular}

(c) Vibration acceleration in the side span $\left(a_{b s}\right)$

\begin{tabular}{|c|c|c|c|c|c|c|c|c|}
\hline \multirow{2}{*}{ Factor } & \multirow{2}{*}{$S_{j}$} & \multirow{2}{*}{ dof } & \multicolumn{3}{|c|}{ Initial } & \multicolumn{3}{|c|}{ Modification } \\
\hline & & & $\sigma_{j}$ & $F$ & $\alpha$ & $\sigma_{j}$ & $F$ & $\alpha$ \\
\hline B & 0.0477 & 2 & 0.0239 & 16.99 & 0.10 & 0.0239 & 12.57 & 0.01 \\
\hline $\mathrm{C}$ & 0.0135 & 2 & 0.0068 & 4.82 & 0.25 & 0.0068 & 3.57 & 0.10 \\
\hline $\mathrm{D}$ & 0.1598 & 2 & 0.0799 & 56.92 & 0.05 & 0.0799 & 42.10 & 0.01 \\
\hline $\mathrm{E}$ & 0.0531 & 2 & 0.0266 & 18.92 & 0.10 & 0.0266 & 13.99 & 0.01 \\
\hline $\mathrm{F}$ & 0.0121 & 2 & 0.0061 & 4.31 & 0.25 & 0.0061 & 3.19 & 0.10 \\
\hline G & 0.0069 & 2 & 0.0034 & 2.44 & $>0.25$ & - & - & \\
\hline $\mathrm{H}$ & 0.0010 & 2 & 0.0005 & 0.37 & $>0.25$ & - & - & \\
\hline I & 0.0181 & 2 & 0.0091 & 6.45 & 0.25 & 0.0091 & 4.77 & 0.05 \\
\hline $\mathrm{J}$ & 0.0465 & 2 & 0.0232 & 16.56 & 0.10 & 0.0232 & 12.25 & 0.01 \\
\hline K & 0.0114 & 2 & 0.0057 & 4.05 & 0.25 & 0.0057 & 2.99 & 0.25 \\
\hline
\end{tabular}


(c) Continued.

\begin{tabular}{|c|c|c|c|c|c|c|c|c|}
\hline \multirow{2}{*}{ Factor } & \multirow{2}{*}{$S_{j}$} & \multirow{2}{*}{ dof } & \multicolumn{3}{|c|}{ Initial } & \multicolumn{3}{|c|}{ Modification } \\
\hline & & & $\sigma_{j}$ & $F$ & $\alpha$ & $\sigma_{j}$ & $F$ & $\alpha$ \\
\hline $\mathrm{L}$ & 0.0045 & 2 & 0.0022 & 1.60 & $>0.25$ & - & - & \\
\hline M & 0.0249 & 2 & 0.0125 & 8.88 & 0.25 & 0.0125 & 6.57 & 0.05 \\
\hline Error & 0.0028 & 2 & 0.0014 & & & 0.0019 & & \\
\hline Sum & 0.4024 & 26 & & & & & & \\
\hline
\end{tabular}

(d) Vibration acceleration in the middle span $\left(a_{b m}\right)$

\begin{tabular}{|c|c|c|c|c|c|c|c|c|}
\hline \multirow{2}{*}{ Factor } & \multirow{2}{*}{$S_{j}$} & \multirow{2}{*}{ dof } & \multicolumn{3}{|c|}{ Initial } & \multicolumn{3}{|c|}{ Modification } \\
\hline & & & $\sigma_{j}$ & $F$ & $\alpha$ & $\sigma_{j}$ & $F$ & $\alpha$ \\
\hline $\mathrm{B}$ & 0.3544 & 2 & 0.1772 & 30.63 & 0.05 & 0.1772 & 47.46 & 0.01 \\
\hline $\mathrm{C}$ & 0.3096 & 2 & 0.1548 & 26.76 & 0.05 & 0.1548 & 41.46 & 0.01 \\
\hline $\mathrm{D}$ & 0.5061 & 2 & 0.2531 & 43.74 & 0.05 & 0.2531 & 67.78 & 0.01 \\
\hline $\mathrm{E}$ & 0.3331 & 2 & 0.1666 & 28.79 & 0.05 & 0.1666 & 44.61 & 0.01 \\
\hline $\mathrm{F}$ & 0.0093 & 2 & 0.0046 & 0.80 & $>0.25$ & - & - & \\
\hline G & 0.0115 & 2 & 0.0057 & 0.99 & $>0.25$ & - & - & \\
\hline $\mathrm{H}$ & 0.0102 & 2 & 0.0051 & 0.88 & $>0.25$ & - & - & \\
\hline I & 0.0315 & 2 & 0.0158 & 2.72 & $>0.25$ & 0.0158 & 4.22 & 0.05 \\
\hline $\mathrm{J}$ & 0.0403 & 2 & 0.0202 & 3.48 & 0.25 & 0.0202 & 5.40 & 0.05 \\
\hline K & 0.0012 & 2 & 0.0006 & 0.10 & $>0.25$ & - & - & \\
\hline $\mathrm{L}$ & 0.0011 & 2 & 0.0006 & 0.10 & $>0.25$ & - & - & \\
\hline $\mathrm{M}$ & 0.0402 & 2 & 0.0201 & 3.48 & 0.25 & 0.0201 & 5.39 & 0.05 \\
\hline Error & 0.0116 & 2 & 0.0058 & & & 0.0037 & & \\
\hline Sum & 1.6601 & 26 & & & & & & \\
\hline
\end{tabular}

(e) Vibration acceleration of the vehicle body $\left(a_{v}\right)$

\begin{tabular}{|c|c|c|c|c|c|c|c|c|}
\hline \multirow{2}{*}{ Factor } & \multirow{2}{*}{$S_{j}$} & \multirow{2}{*}{ dof } & \multicolumn{3}{|c|}{ Initial } & \multicolumn{3}{|c|}{ Modification } \\
\hline & & & $\sigma_{j}$ & $F$ & $\alpha$ & $\sigma_{j}$ & $F$ & $\alpha$ \\
\hline B & 1.3451 & 2 & 0.6726 & 12.43 & 0.10 & 0.6726 & 17.11 & 0.01 \\
\hline $\mathrm{C}$ & 1.0364 & 2 & 0.5182 & 9.58 & 0.10 & 0.5182 & 13.18 & 0.01 \\
\hline $\mathrm{D}$ & 0.8230 & 2 & 0.4115 & 7.60 & 0.25 & 0.4115 & 10.47 & 0.05 \\
\hline $\mathrm{E}$ & 0.4458 & 2 & 0.2229 & 4.12 & 0.25 & 0.2229 & 5.67 & 0.05 \\
\hline $\mathrm{F}$ & 0.6294 & 2 & 0.3147 & 5.81 & 0.25 & 0.3147 & 8.01 & 0.05 \\
\hline G & 0.0936 & 2 & 0.0468 & 0.86 & $>0.25$ & - & - & \\
\hline $\mathrm{H}$ & 5.4978 & 2 & 2.7489 & 50.79 & 0.05 & 2.7489 & 69.93 & 0.01 \\
\hline I & 1.8752 & 2 & 0.9376 & 17.32 & 0.10 & 0.9376 & 23.85 & 0.01 \\
\hline $\mathrm{J}$ & 0.9799 & 2 & 0.4899 & 9.05 & 0.10 & 0.4899 & 12.46 & 0.01 \\
\hline K & 1.5926 & 2 & 0.7963 & 14.71 & 0.10 & 0.7963 & 20.26 & 0.01 \\
\hline $\mathrm{L}$ & 0.8165 & 2 & 0.4082 & 7.54 & 0.25 & 0.4082 & 10.38 & 0.05 \\
\hline M & 0.0340 & 2 & 0.0170 & 0.31 & $>0.25$ & - & - & \\
\hline Error & 0.1082 & 2 & 0.0541 & & & 0.0393 & & \\
\hline Sum & 15.2776 & 26 & & & & & & \\
\hline
\end{tabular}

boundary conditions are no longer the same as the design state.

(2) The empirical formulas on the first two natural frequencies of the continuous girder bridge with odd span are given by the numerical simulations. Similarly, the empirical formulas on the first and the third natural frequencies of the continuous girder bridge with even span are obtained. They can be used for calculating the dynamic load allowance in the mid-span cross-section and the pier-top crosssection based on the current code of bridge design in China, respectively. Also, according to these formulas, the factors influencing natural frequencies are more clearly seen, which may give a better guideline for 
TABLE 12: Design of the table header.

\begin{tabular}{|c|c|c|c|c|c|c|c|c|c|c|c|c|c|c|c|}
\hline Column & 1 & 2 & 3 & 4 & 5 & 6 & 7 & 8 & 9 & 10 & 11 & 12 & 13 & 14 & 15 \\
\hline Factor & A & $\mathrm{D}$ & $A \times D$ & B & $A \times B$ & $\mathrm{D} \times \mathrm{B}$ & $\mathrm{E}$ & $\mathrm{C}$ & $\mathrm{A} \times \mathrm{C}$ & $\mathrm{D} \times \mathrm{C}$ & $\mathrm{H}$ & $\mathrm{B} \times \mathrm{C}$ & I & $\mathrm{J}$ & Non \\
\hline
\end{tabular}

TABLE 13: Results of numerical simulation with interaction.

\begin{tabular}{|c|c|c|c|c|c|c|}
\hline Run & $f_{1}(\mathrm{~Hz})$ & $\mathrm{DLA}_{s}$ & $\mathrm{DLA}_{m}$ & $a_{b s}\left(\mathrm{~m} / \mathrm{s}^{2}\right)$ & $a_{b m}\left(\mathrm{~m} / \mathrm{s}^{2}\right)$ & $a_{v}\left(\mathrm{~m} / \mathrm{s}^{2}\right)$ \\
\hline 1 & 7.40 & 1.212 & 1.123 & 0.2164 & 0.0981 & 1.6398 \\
\hline 2 & 6.34 & 1.170 & 1.163 & 0.0726 & 0.0651 & 1.6830 \\
\hline 3 & 3.73 & 1.259 & 1.583 & 0.0565 & 0.1310 & 1.4709 \\
\hline 4 & 3.20 & 1.192 & 1.181 & 0.0802 & 0.1128 & 1.2788 \\
\hline 5 & 5.15 & 1.184 & 1.149 & 0.1469 & 0.0606 & 1.2814 \\
\hline 6 & 4.95 & 1.279 & 1.363 & 0.0505 & 0.0857 & 1.8366 \\
\hline 7 & 3.25 & 1.195 & 1.629 & 0.0770 & 0.1351 & 1.6609 \\
\hline 8 & 3.12 & 1.245 & 1.783 & 0.0932 & 0.1486 & 1.3401 \\
\hline 9 & 6.61 & 1.504 & 1.410 & 0.3277 & 0.1753 & 3.2438 \\
\hline 10 & 5.67 & 1.355 & 1.421 & 0.1105 & 0.1190 & 3.2590 \\
\hline 11 & 4.17 & 1.343 & 1.426 & 0.1617 & 0.2024 & 2.4870 \\
\hline 12 & 3.57 & 1.496 & 2.011 & 0.2926 & 0.3618 & 3.2189 \\
\hline 13 & 5.76 & 1.638 & 1.404 & 0.2203 & 0.2013 & 3.4707 \\
\hline 14 & 5.53 & 1.299 & 1.488 & 0.1322 & 0.1227 & 2.7466 \\
\hline 15 & 2.90 & 1.357 & 3.016 & 0.1019 & 0.3588 & 2.9297 \\
\hline 16 & 2.79 & 1.685 & 2.495 & 0.2080 & 0.3878 & 2.8570 \\
\hline
\end{tabular}

TABLE 14: Range analysis of numerical simulation with interaction.

\begin{tabular}{lccccccccccccccc}
\hline Index & $\mathrm{A}$ & $\mathrm{D}$ & $\mathrm{A} \times \mathrm{D}$ & $\mathrm{B}$ & $\mathrm{A} \times \mathrm{B}$ & $\mathrm{D} \times \mathrm{B}$ & $\mathrm{E}$ & $\mathrm{C}$ & $\mathrm{A} \times \mathrm{C}$ & $\mathrm{D} \times \mathrm{C}$ & $\mathrm{H}$ & $\mathrm{B} \times \mathrm{C}$ & $\mathrm{I}$ & $\mathrm{J}$ \\
\hline $\mathrm{DLA}_{s}$ & 0.242 & 0.044 & 0.026 & 0.016 & 0.005 & 0.004 & 0.027 & 0.004 & 0.005 & 0.030 & 0.034 & 0.112 & 0.130 & 0.043 \\
$\mathrm{DLA}_{m}$ & 0.462 & 0.376 & 0.157 & 0.576 & 0.231 & 0.305 & 0.199 & 0.021 & 0.019 & 0.038 & 0.220 & 0.067 & 0.059 & 0.099 \\
$a_{b s}\left(\mathrm{~m} / \mathrm{s}^{2}\right)$ & 0.095 & 0.036 & 0.021 & 0.026 & 0.019 & 0.008 & 0.023 & 0.034 & 0.016 & 0.018 & 0.008 & 0.103 & 0.033 & 0.026 \\
$a_{b m}\left(\mathrm{~m} / \mathrm{s}^{2}\right)$ & 0.136 & 0.029 & 0.024 & 0.114 & 0.059 & 0.026 & 0.012 & 0.005 & 0.008 & 0.008 & 0.030 & 0.041 & 0.040 & 0.017 \\
$a_{v}\left(\mathrm{~m} / \mathrm{s}^{2}\right)$ & 1.503 & 0.020 & 0.031 & 0.240 & 0.067 & 0.103 & 0.011 & 0.004 & 0.017 & 0.145 & 0.241 & 0.032 & 0.310 & 0.088 \\
\hline
\end{tabular}

the design and evaluation of dynamic performance of bridges.

(3) The dynamic responses in the side span, including the DLA and the vibration acceleration, are always largely different from those in the middle span. In addition, the effects of different factors on different dynamic responses of the vehicle-bridge system are various. In other words, the effects of factors on dynamic responses are dependent on both the selected position and the type of the responses (DLA or vibration acceleration).

(4) Based on the traditional method, when one factor is studied, the others should be fixed. Some significant factors affecting the dynamic responses of the vehiclebridge system are roughly identified and selected. They are the pavement roughness, the length of the main span, the ratio between the side span and the middle span, the number of spans, the weight of the bridge and the vehicle, and the upper stiffness and damping of the vehicle.
(5) The orthogonal experimental design is introduced in this study for the dynamic responses analysis of the vehicle-bridge coupled vibration system. To efficiently reduce the experimental runs, the conventional orthogonal design is divided into two phases. In the first phase, the main effects (single factor) are analyzed without any interaction effects. Based on the results from the first phase, the interaction effects of some of the most important factors are discussed in the second phase. It has been proved that the interaction effects cannot be ignored.

In the end, it has to be emphasized that the proposed method of the orthogonal experimental design greatly reduces calculation cost. And it is efficient and rational enough to study multifactor problems. The proposed method is used for not only the analysis of influence factors but also the analysis of regression. And it can be applied in all types of bridges, other than just the girder bridge. Furthermore, it provides a good way to obtain more rational empirical formulas of the DLA and other dynamic responses, which may be adopted in the codes of design and evaluation. 
TABLE 15: Various analysis of numerical simulation with interaction.

(a) Dynamic load allowance in the side span $\left(\mathrm{DLA}_{s}\right)$

\begin{tabular}{|c|c|c|c|c|c|c|c|c|}
\hline \multirow{2}{*}{ Factor } & \multirow{2}{*}{$S_{j}$} & \multirow{2}{*}{ dof } & \multicolumn{3}{|c|}{ Initial } & \multicolumn{3}{|c|}{ Modification } \\
\hline & & & $\sigma_{j}$ & $F$ & $\alpha$ & $\sigma_{j}$ & $F$ & $\alpha$ \\
\hline$\overline{\mathrm{A}}$ & 0.2348 & 1 & 0.2348 & 25.47 & 0.25 & 0.2348 & 24.58 & 0.01 \\
\hline $\mathrm{D}$ & 0.0077 & 1 & 0.0077 & 0.83 & $>0.25$ & 0.0077 & 0.80 & $>0.25$ \\
\hline $\mathrm{A} \times \mathrm{D}$ & 0.0028 & 1 & 0.0028 & 0.30 & $>0.25$ & 0.0028 & 0.29 & $>0.25$ \\
\hline $\mathrm{B}$ & 0.0011 & 1 & 0.0011 & 0.12 & $>0.25$ & 0.0011 & 0.11 & $>0.25$ \\
\hline $\mathrm{A} \times \mathrm{B}$ & 0.0001 & 1 & 0.0001 & 0.01 & $>0.25$ & - & - & \\
\hline $\mathrm{D} \times \mathrm{B}$ & 0.0001 & 1 & 0.0001 & 0.01 & $>0.25$ & - & - & \\
\hline $\mathrm{E}$ & 0.0029 & 1 & 0.0029 & 0.32 & $>0.25$ & 0.0029 & 0.31 & $>0.25$ \\
\hline $\mathrm{C}$ & 0.0001 & 1 & 0.0001 & 0.01 & $>0.25$ & - & - & \\
\hline $\mathrm{A} \times \mathrm{C}$ & 0.0001 & 1 & 0.0001 & 0.01 & $>0.25$ & - & - & \\
\hline $\mathrm{D} \times \mathrm{C}$ & 0.0036 & 1 & 0.0036 & 0.39 & $>0.25$ & 0.0036 & 0.37 & $>0.25$ \\
\hline $\mathrm{H}$ & 0.0045 & 1 & 0.0045 & 0.49 & $>0.25$ & 0.0045 & 0.47 & $>0.25$ \\
\hline $\mathrm{B} \times \mathrm{C}$ & 0.0506 & 1 & 0.0506 & 5.49 & $>0.25$ & 0.0506 & 5.30 & 0.10 \\
\hline I & 0.0675 & 1 & 0.0675 & 7.33 & 0.25 & 0.0675 & 7.07 & 0.05 \\
\hline $\mathrm{J}$ & 0.0074 & 1 & 0.0074 & 0.80 & $>0.25$ & 0.0074 & 0.78 & $>0.25$ \\
\hline Error & 0.0092 & 1 & 0.0092 & & & 0.0095 & & \\
\hline Sum & 0.3924 & 15 & & & & & & \\
\hline
\end{tabular}

(b) Dynamic load allowance in the middle span $\left(\mathrm{DLA}_{m}\right)$

\begin{tabular}{|c|c|c|c|c|c|c|c|c|}
\hline \multirow{2}{*}{ Factor } & \multirow{2}{*}{$S_{j}$} & \multirow{2}{*}{ dof } & \multicolumn{3}{|c|}{ Initial } & \multicolumn{3}{|c|}{ Modification } \\
\hline & & & $\sigma_{j}$ & $F$ & $\alpha$ & $\sigma_{j}$ & $F$ & $\alpha$ \\
\hline A & 0.8551 & 1 & 0.8551 & 5.63 & $>0.25$ & 0.8551 & 4.44 & 0.10 \\
\hline $\mathrm{D}$ & 0.5659 & 1 & 0.5659 & 3.72 & $>0.25$ & 0.5659 & 2.94 & 0.15 \\
\hline $\mathrm{A} \times \mathrm{D}$ & 0.0991 & 1 & 0.0991 & 0.65 & $>0.25$ & 0.0991 & 0.51 & $>0.25$ \\
\hline B & 1.3252 & 1 & 1.3252 & 8.72 & 0.25 & 1.3252 & 6.88 & 0.05 \\
\hline $\mathrm{A} \times \mathrm{B}$ & 0.2134 & 1 & 0.2134 & 1.40 & $>0.25$ & 0.2134 & 1.11 & $>0.25$ \\
\hline $\mathrm{D} \times \mathrm{B}$ & 0.3714 & 1 & 0.3714 & 2.44 & $>0.25$ & 0.3714 & 1.93 & 0.15 \\
\hline $\mathrm{E}$ & 0.1582 & 1 & 0.1582 & 1.04 & $>0.25$ & 0.1582 & 0.82 & $>0.25$ \\
\hline $\mathrm{C}$ & 0.0017 & 1 & 0.0017 & 0.01 & $>0.25$ & - & - & \\
\hline $\mathrm{A} \times \mathrm{C}$ & 0.0015 & 1 & 0.0015 & 0.01 & $>0.25$ & - & - & \\
\hline $\mathrm{D} \times \mathrm{C}$ & 0.0057 & 1 & 0.0057 & 0.04 & $>0.25$ & - & - & \\
\hline $\mathrm{H}$ & 0.1941 & 1 & 0.1941 & 1.28 & $>0.25$ & 0.1941 & 1.01 & $>0.25$ \\
\hline $\mathrm{B} \times \mathrm{C}$ & 0.0179 & 1 & 0.0179 & 0.12 & $>0.25$ & - & - & \\
\hline I & 0.0138 & 1 & 0.0138 & 0.09 & $>0.25$ & - & - & \\
\hline $\mathrm{J}$ & 0.0395 & 1 & 0.0395 & 0.26 & $>0.25$ & 0.0395 & 0.21 & $>0.25$ \\
\hline Error & 0.1520 & 1 & 0.1520 & & & 0.1926 & & \\
\hline Sum & 4.0147 & 15 & & & & & & \\
\hline
\end{tabular}

(c) Vibration acceleration in the side span $\left(a_{b s}\right)$

\begin{tabular}{lcccccccc}
\hline \multirow{2}{*}{ Factor } & \multirow{2}{*}{$S_{j}$} & dof & \multicolumn{3}{c}{ Initial } & \multicolumn{3}{c}{ Modification } \\
& & & $\sigma_{j}$ & $F$ & $\alpha$ & $\sigma_{j}$ & $F$ \\
\hline $\mathrm{A}$ & 0.0363 & 1 & 0.0363 & 59.14 & $>0.25$ & 0.0363 & 0.67 & 0.10 \\
$\mathrm{D}$ & 0.0052 & 1 & 0.0052 & 8.46 & $>0.25$ & 0.0052 & 0.10 & 0.15 \\
$\mathrm{~A} \times \mathrm{D}$ & 0.0018 & 1 & 0.0018 & 3.01 & $>0.25$ & 0.0018 & 0.03 & $>0.25$ \\
$\mathrm{~B}$ & 0.0027 & 1 & 0.0027 & 4.32 & 0.25 & 0.0027 & 0.05 & 0.05 \\
$\mathrm{~A} \times \mathrm{B}$ & 0.0015 & 1 & 0.0015 & 2.39 & $>0.25$ & 0.0015 & 0.03 & $>0.25$ \\
$\mathrm{D} \times \mathrm{B}$ & 0.0003 & 1 & 0.0003 & 0.45 & $>0.25$ & 0.0003 & 0.01 & 0.15 \\
$\mathrm{E}$ & 0.0021 & 1 & 0.0021 & 3.44 & $>0.25$ & 0.0021 & 0.04 & $>0.25$ \\
$\mathrm{C}$ & 0.0045 & 1 & 0.0045 & 7.36 & $>0.25$ & - & - & \\
\hline
\end{tabular}


(c) Continued

\begin{tabular}{|c|c|c|c|c|c|c|c|c|}
\hline \multirow{2}{*}{ Factor } & \multirow{2}{*}{$S_{j}$} & \multirow{2}{*}{ dof } & \multicolumn{3}{|c|}{ Initial } & \multicolumn{3}{|c|}{ Modification } \\
\hline & & & $\sigma_{j}$ & $F$ & $\alpha$ & $\sigma_{j}$ & $F$ & $\alpha$ \\
\hline$A \times C$ & 0.0011 & 1 & 0.0011 & 1.77 & $>0.25$ & - & - & \\
\hline $\mathrm{D} \times \mathrm{C}$ & 0.0013 & 1 & 0.0013 & 2.12 & $>0.25$ & - & - & \\
\hline $\mathrm{H}$ & 0.0003 & 1 & 0.0003 & 0.42 & $>0.25$ & 0.0003 & 0.00 & $>0.25$ \\
\hline $\mathrm{B} \times \mathrm{C}$ & 0.0423 & 1 & 0.0423 & 68.95 & $>0.25$ & - & - & \\
\hline I & 0.0043 & 1 & 0.0043 & 7.01 & $>0.25$ & - & - & \\
\hline $\mathrm{J}$ & 0.0027 & 1 & 0.0027 & 4.43 & $>0.25$ & 0.0027 & 0.05 & $>0.25$ \\
\hline Error & 0.0006 & 1 & 0.0006 & & & 0.0541 & & \\
\hline Sum & 0.1069 & 15 & & & & & & \\
\hline
\end{tabular}

(d) Vibration acceleration in the middle span $\left(a_{b m}\right)$

\begin{tabular}{|c|c|c|c|c|c|c|c|c|}
\hline \multirow{2}{*}{ Factor } & \multirow{2}{*}{$S_{j}$} & \multirow{2}{*}{ dof } & \multicolumn{3}{|c|}{ Initial } & \multicolumn{3}{|c|}{ Modification } \\
\hline & & & $\sigma_{j}$ & $F$ & $\alpha$ & $\sigma_{j}$ & $F$ & $\alpha$ \\
\hline $\mathrm{A}$ & 0.0745 & 1 & 0.0745 & 178.69 & 0.05 & 0.0745 & 27.12 & 0.01 \\
\hline $\mathrm{D}$ & 0.0035 & 1 & 0.0035 & 8.29 & 0.25 & 0.0035 & 1.26 & $>0.25$ \\
\hline $\mathrm{A} \times \mathrm{D}$ & 0.0022 & 1 & 0.0022 & 5.35 & $>0.25$ & 0.0022 & 0.81 & $>0.25$ \\
\hline $\mathrm{B}$ & 0.0518 & 1 & 0.0518 & 124.28 & 0.10 & 0.0518 & 18.86 & 0.01 \\
\hline $\mathrm{A} \times \mathrm{B}$ & 0.0141 & 1 & 0.0141 & 33.75 & 0.25 & 0.0141 & 5.12 & 0.10 \\
\hline $\mathrm{D} \times \mathrm{B}$ & 0.0027 & 1 & 0.0027 & 6.58 & 0.25 & 0.0027 & 1.00 & $>0.25$ \\
\hline $\mathrm{E}$ & 0.0006 & 1 & 0.0006 & 1.38 & $>0.25$ & - & - & \\
\hline $\mathrm{C}$ & 0.0001 & 1 & 0.0001 & 0.25 & $>0.25$ & - & - & \\
\hline $\mathrm{A} \times \mathrm{C}$ & 0.0003 & 1 & 0.0003 & 0.66 & $>0.25$ & - & - & \\
\hline $\mathrm{D} \times \mathrm{C}$ & 0.0002 & 1 & 0.0002 & 0.59 & $>0.25$ & - & - & \\
\hline $\mathrm{H}$ & 0.0037 & 1 & 0.0037 & 8.81 & 0.25 & 0.0037 & 1.34 & $>0.25$ \\
\hline $\mathrm{B} \times \mathrm{C}$ & 0.0067 & 1 & 0.0067 & 16.00 & 0.25 & 0.0067 & 2.43 & 0.25 \\
\hline I & 0.0064 & 1 & 0.0064 & 15.36 & 0.25 & 0.0064 & 2.33 & 0.25 \\
\hline $\mathrm{J}$ & 0.0011 & 1 & 0.0011 & 2.71 & $>0.25$ & - & - & \\
\hline Error & 0.0004 & 1 & 0.0004 & & & 0.0027 & & \\
\hline Sum & 0.1683 & 15 & & & & & & \\
\hline
\end{tabular}

(e) Vibration acceleration of the vehicle body $\left(a_{v}\right)$

\begin{tabular}{|c|c|c|c|c|c|c|c|c|}
\hline \multirow{2}{*}{ Factor } & \multirow{2}{*}{$S_{j}$} & \multirow{2}{*}{ dof } & \multicolumn{3}{|c|}{ Initial } & \multicolumn{3}{|c|}{ Modification } \\
\hline & & & $\sigma_{j}$ & $F$ & $\alpha$ & $\sigma_{j}$ & $F$ & $\alpha$ \\
\hline $\bar{A}$ & 9.0320 & 1 & 9.0320 & 436.16 & 0.05 & 9.0320 & 323.17 & 0.01 \\
\hline $\mathrm{D}$ & 0.0016 & 1 & 0.0016 & 0.08 & $>0.25$ & - & - & \\
\hline $\mathrm{A} \times \mathrm{D}$ & 0.0039 & 1 & 0.0039 & 0.19 & $>0.25$ & - & - & \\
\hline $\mathrm{B}$ & 0.2298 & 1 & 0.2298 & 11.10 & 0.25 & 0.2298 & 8.22 & 0.05 \\
\hline $\mathrm{A} \times \mathrm{B}$ & 0.0180 & 1 & 0.0180 & 0.87 & $>0.25$ & 0.0180 & 0.65 & $>0.25$ \\
\hline $\mathrm{D} \times \mathrm{B}$ & 0.0423 & 1 & 0.0423 & 2.04 & $>0.25$ & 0.0423 & 1.51 & $>0.25$ \\
\hline $\mathrm{E}$ & 0.0005 & 1 & 0.0005 & 0.02 & $>0.25$ & - & - & \\
\hline $\mathrm{C}$ & 0.0001 & 1 & 0.0001 & 0.00 & $>0.25$ & - & - & \\
\hline $\mathrm{A} \times \mathrm{C}$ & 0.0011 & 1 & 0.0011 & 0.06 & $>0.25$ & - & - & \\
\hline $\mathrm{D} \times \mathrm{C}$ & 0.0842 & 1 & 0.0842 & 4.06 & $>0.25$ & 0.0842 & 3.01 & 0.25 \\
\hline $\mathrm{H}$ & 0.2321 & 1 & 0.2321 & 11.21 & 0.25 & 0.2321 & 8.31 & 0.05 \\
\hline $\mathrm{B} \times \mathrm{C}$ & 0.0041 & 1 & 0.0041 & 0.20 & $>0.25$ & 0.0041 & 0.15 & $>0.25$ \\
\hline I & 0.3842 & 1 & 0.3842 & 18.55 & 0.25 & 0.3842 & 13.75 & 0.01 \\
\hline $\mathrm{J}$ & 0.0312 & 1 & 0.0312 & 1.50 & $>0.25$ & 0.0312 & 1.11 & $>0.25$ \\
\hline Error & 0.0207 & 1 & 0.0207 & & & 0.0279 & & \\
\hline Sum & 10.0859 & 15 & & & & & & \\
\hline
\end{tabular}




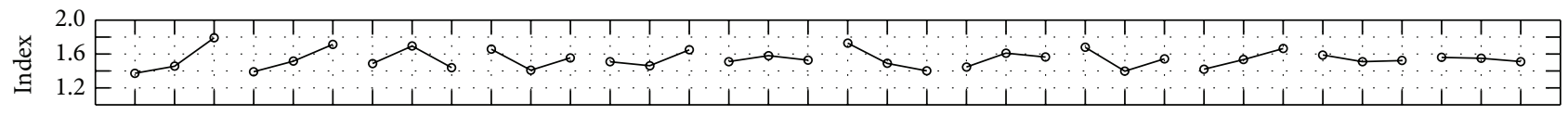

B1 B2 B3 C1 C2 C3 D1 D2 D3 E1 E2 E3 F1 F2 F3 G1 G2 G3 H1 H2 H3 I1 I2 I3 J1 J2 J3 K1 K2 K3 L1 L2 L3 M1 M2 M3

Factors and levels

(a) Trend plot between factors and the DLA in side span

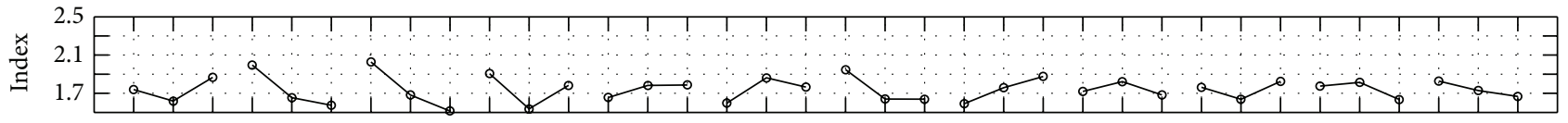

B1 B2 B3 C1 C2 C3 D1 D2 D3 E1 E2 E3 F1 F2 F3 G1 G2 G3 H1 H2 H3 I1 I2 I3 J1 J2 J3 K1 K2 K3 L1 L2 L3 M1 M2 M3

Factors and levels

(b) Trend plot between factors and the DLA in middle span

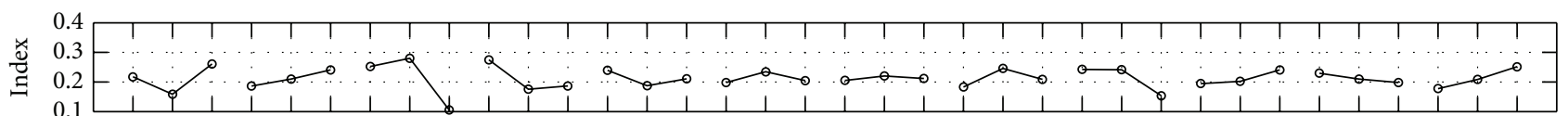

B1 B2 B3 C1 C2 C3 D1 D2 D3 E1 E2 E3 F1 F2 F3 G1 G2 G3 H1 H2 H3 I1 I2 I3 J1 J2 J3 K1 K2 K3 L1 L2 L3 M1 M2 M3

Factors and levels

(c) Trend plot between factors and the acceleration in side span

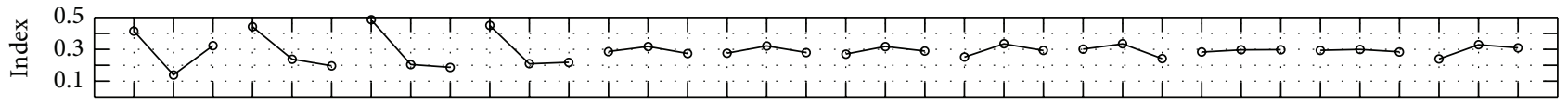

B1 B2 B3 C1 C2 C3 D1 D2 D3 E1 E2 E3 F1 F2 F3 G1 G2 G3 H1 H2 H3 I1 I2 I3 J1 J2 J3 K1 K2 K3 L1 L2 L3 M1 M2 M3

Factors and levels

(d) Trend plot between factors and the acceleration in middle span

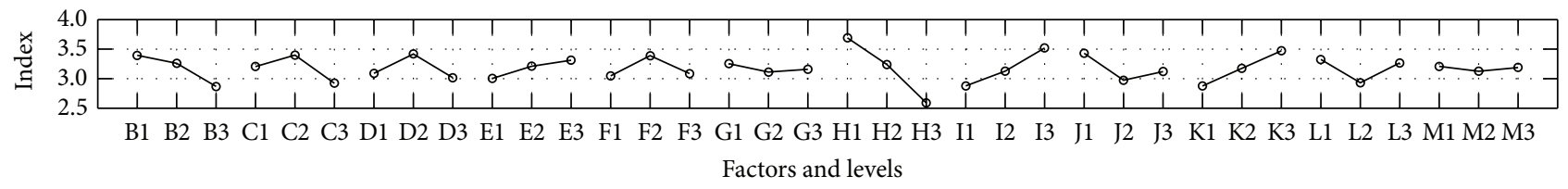

(e) Trend plot between factors and the acceleration of the vehicle body

FIgURE 18: Trend plot between the factors and the tested index.

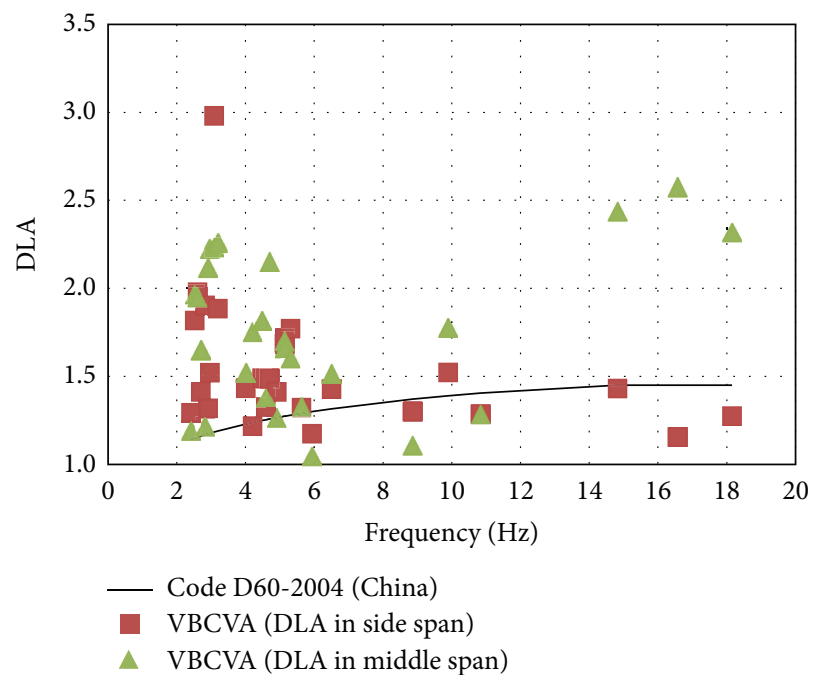

(a) The sample without interaction

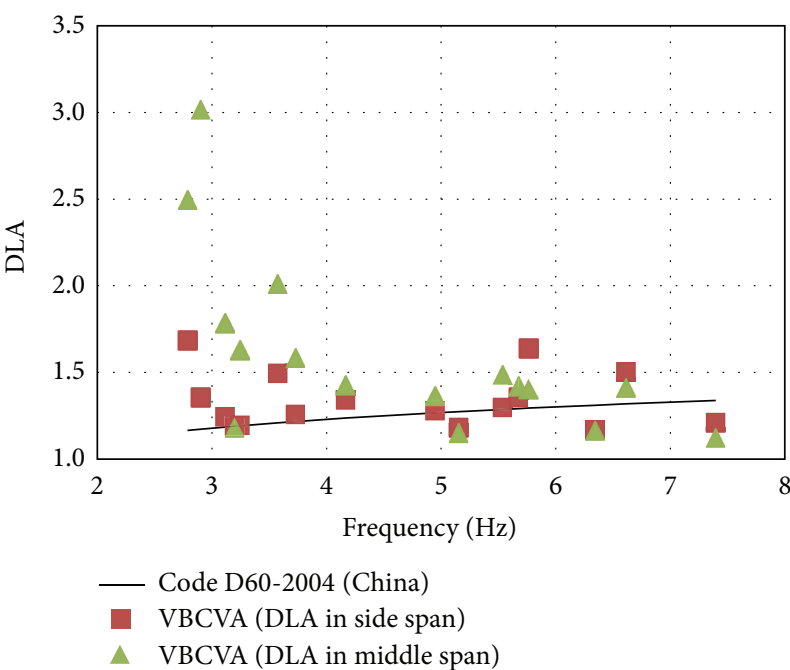

(b) The sample with interaction

FIGURE 19: Comparison with the current code. 


\section{Conflict of Interests}

The authors declare that there is no conflict of interests regarding the publication of this paper.

\section{Acknowledgments}

The research reported herein was sponsored by the China Scholarship Council (the 2013 China State-Sponsored Postgraduate Study Abroad Program), the National Natural Science Foundation of China (nos. 51308465, 50678051, and 51108132, U1234208), and the Fundamental Research Funds for the Central Universities (no. 2682014CX004EM). The authors would like to express their deep gratitude to all the sponsors for the financial aid.

\section{References}

[1] D. I. McLean and M. L. Marsh, Dynamic Impact Factors for Bridges, Transportation Research Board, Washington, DC, USA, 1998.

[2] ASCE Committee on Loads and Forces on Bridges of the Committee on Bridges of the Structural Division, "Bridge loading: research needed," ASCE Journal of the Structural Division, vol. 108, no. 5, pp. 1012-1020, 1982.

[3] ASCE Committee on Loads and Forces on Bridges of the Committee on Bridges of the Structural Division, "Recommendation design loads for bridges," Journal of the Structural Division, vol. 107, no. 7, pp. 1161-1213, 1981.

[4] P. F. Csagoly and R. A. Dorton, "The development of the Ontario Highway Bridge Design Code," Transportation Research Record, no. 655 , pp. 1-12, 1978.

[5] J. R. Billing and R. Green, "Design provisions for dynamic loading of highway bridges," Transportation Research Record, vol. 950, pp. 94-103, 1984.

[6] D. B. Ashebo, Evaluation of dynamic loads for highway bridges [Ph.D. thesis], The Hong Kong Polytechnic University, Hong Kong, 2006.

[7] B. Bakht and S. G. Pinjarkar, Dynamic Testing of Highway Bridges-A Review, Ministry of Transportation, Ontario, Canada, 1989.

[8] OHBDC, Ontario Highway Bridge Design Code, Ontario Ministry of Transportation and Communications, Ontario, Canada, 1983.

[9] M. Samaan, J. B. Kennedy, and K. Sennah, "Impact factors for curved continuous composite multiple-box girder bridges," Journal of Bridge Engineering, vol. 12, no. 1, pp. 80-88, 2007.

[10] K. M. Sennah, X. Zhang, and J. B. Kennedy, "Impact factors for horizontally curved composite box girder bridges," Journal of Bridge Engineering, vol. 9, no. 6, pp. 512-520, 2004.

[11] J. Senthilvasan, D. P. Thambiratnam, and G. H. Brameld, "Dynamic response of a curved bridge under moving truck load," Engineering Structures, vol. 24, no. 10, pp. 1283-1293, 2002.

[12] S. Komatsu and H. Nakai, "Fundamental study on forced vibration of curved girder bridges," Transactions of the Japan Society of Civil Engineers, vol. 2, pp. 37-42, 1970.

[13] K. M. Sennah, Load distribution factor and dynamic characteristics of curved composite concrete deck-steel cellular bridges [Ph.D. thesis], University of Windsor, Ontario, Canada.

[14] R. Cantieni, Dynamic Load Testing of Highway Bridges, Transportation Research Board, Washington, DC, USA, 1984.
[15] J. R. Billing, Estimation of the Natural Frequencies of Continuous Multi-Span Bridges, Ontario Ministry of Transportation and Communications, Ontario, Canada, 1979.

[16] Q. F. Gao, Z. L. Wang, Y. Liu, and B. Q. Guo, "Modified formula of estimating fundamental frequency of girder bridge with uniform cross-section," Advanced Engineering Forum, vol. 5, pp. 177-182, 2012.

[17] Q. Gao, Z. Wang, and B. Guo, "Modified formula of estimating fundamental frequency of girder bridge with variable crosssection," Key Engineering Materials, vol. 540, pp. 99-106, 2013.

[18] I. Mohseni, A. K. A. Rashid, and J. Kang, "A simplified method to estimate the fundamental frequency of skew continuous multicell box-girder bridges," Latin American Journal of Solids and Structures, vol. 11, no. 4, pp. 649-658, 2014.

[19] P. Paultre, O. Chaallal, and J. Proulx, "Bridge dynamics and dynamic amplification factors-a review of analytical and experimental findings," Canadian Journal of Civil Engineering, vol. 19, no. 2, pp. 260-278, 1992.

[20] AASHO, The AASHO Road Test, Highway Research Board, Washington, DC, USA, 1962.

[21] D. T. Wright and R. Green, Highway Bridge Vibrations, Part II, Ontario Test Program, Queen's University, Ontario, Canada, 1963.

[22] P. F. Csagoly, T. I. Campbell, and A. C. Agarwall, Bridge Vibration Study, Ministry of Transportation and Communications, Ontario, Canada, 1972.

[23] J. Page, Dynamic Wheel Measurements on Motorway Bridges, Transport and Road Research Laboratory, London, UK, 1976.

[24] D. R. Leonard, Dynamic Tests on Highway Bridges, Transport and Road Research Laboratory, London, UK, 1974.

[25] R. Shepard and G. K. Sidwell, "Investigations of the dynamic properties of five concrete bridges," in Proceedings of the 4th Australian Conference on the Mechanics of Structures and Materials, pp. 261-268, University of Queensland, Brisbane, Australia, 1973.

[26] R. Shepard and R. J. Aves, "Impact factors for simple concrete bridges," in Proceedings of the Institution of Civil Engineers, vol. 55, pp. 191-210, 1973.

[27] J. H. Wood and R. Shepard, "Vehicle induced vibrations," Road Research Unit Bulletin 44, 1979.

[28] J. R. Billing, "Dynamic loading and testing of bridges in Ontario," Canadian Journal of Civil Engineering, vol. 11, no. 4, pp. 833-843, 1984.

[29] R. Cantieni, Dynamic Load Tests on Highway Bridges in Switzerland-60 Years of Experience, Federal Laboratories for Testing of Materials, EMPA, Dübendorf, Switzerland, 1983.

[30] A. S. Veletsos, "Analysis of dynamic response of highway bridges," ASCE Journal of the Engineering Division, vol. 93, no. 5, pp. 593-620, 1970.

[31] J. T. Guant, T. Aramraks, M. J. Gutzwiller, and R. H. Lee, Highway Bridge Vibration Studies, Transportation Research Board, Washington, DC, USA, 1977.

[32] M. J. Inbanathan and M. Wieland, "Bridge vibrations due to vehicle moving over rough surface," Journal of Structural Engineering, vol. 113, no. 9, pp. 1994-2008, 1987.

[33] O. Coussy, M. Said, and J.-P. van Hoove, "The influence of random surface irregularities on the dynamic response of bridges under suspended moving loads," Journal of Sound and Vibration, vol. 130, no. 2, pp. 313-320, 1989.

[34] W. Cui, X. Li, S. Zhou, and J. Weng, "Investigation on process parameters of electrospinning system through orthogonal 
experimental design," Journal of Applied Polymer Science, vol. 103, no. 5, pp. 3105-3112, 2007.

[35] F. Kaitai and M. Changxing, Orthogonal and Uniform Experimental Design, Tsinghua University Press, Beijing, China, 2001.

[36] W. F. Kuhfeld, R. D. Tobias, and M. Garratt, "Efficient experimental design with marketing research applications," Journal of Marketing Research, vol. 12, pp. 545-557, 1994.

[37] S. Chen, X. Hong, and C. J. Harris, "Sparse kernel regression modeling using combined locally regularized orthogonal least squares and D-optimality experimental design," IEEE Transactions on Automatic Control, vol. 48, no. 6, pp. 1029-1036, 2003.

[38] A. H. Jesus, Z. Dimitrovová, and M. A. G. Silva, "A statistical analysis of the dynamic response of a railway viaduct," Engineering Structures, vol. 71, pp. 244-259, 2014.

[39] E. S. Hwang and A. S. Nowak, "Simulation of dynamic load for bridges," Journal of Structural Engineering, vol. 117, no. 5, pp. 1413-1434, 1991.

[40] W. Huang, X. Zhang, and G. Hu, "New advance of theory and design on pavement for long-span steel bridge," Journal of Southeast University (Natural Science Edition), vol. 32, no. 3, pp. 480-487, 2002 (Chinese).

[41] P. K. Chatterjee, T. K. Datta, and C. S. Surana, "Vibration of continuous bridges under moving vehicles," Journal of Sound and Vibration, vol. 169, no. 5, pp. 619-632, 1994.

[42] R. Mee, A Comprehensive Guide to Factorial Two-Level Experimentation, Springer, Berlin, Germany, 2009.

[43] L. Q. Ren, Optimum Design and Analysis of Experiments, Higher Education Press, Beijing, China, 2nd edition, 2003, (Chinese).

[44] J. Cheng, H. Zhu, S. Zhong, F. Zheng, and Y. Zeng, "Finite-time filtering for switched linear systems with a mode-dependent average dwell time," Nonlinear Analysis: Hybrid Systems, vol. 15, pp. 145-156, 2015.

[45] T. P. Ryan, Modern Engineering Statistics: Solutions Manual to Accompany, John Wiley \& Sons, Hoboken, NJ, USA, 2000.

[46] D. C. Montgomery, Design and Analysis of Experiments, John Wiley \& Sons, Hoboken, NJ, USA, 2008.

[47] D. Zhang and L. Yu, "Exponential state estimation for Markovian jumping neural networks with time-varying discrete and distributed delays," Neural Networks, vol. 35, pp. 103-111, 2012.

[48] Ministry of Communication of the People's Republic of China, JTG D60-2004 General Code for Design of Highway Bridges and Culverts, China Communication Press, Beijing, China, 2004, (Chinese). 


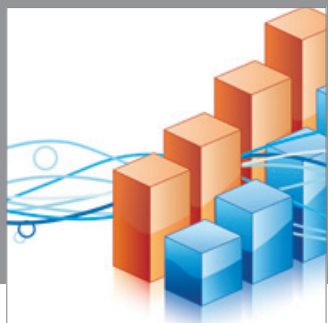

Advances in

Operations Research

mansans

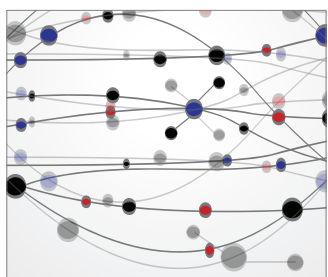

The Scientific World Journal
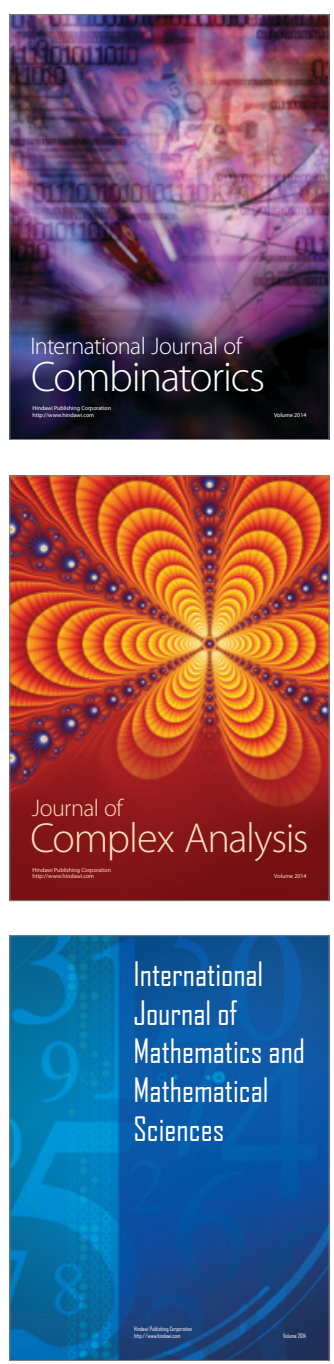
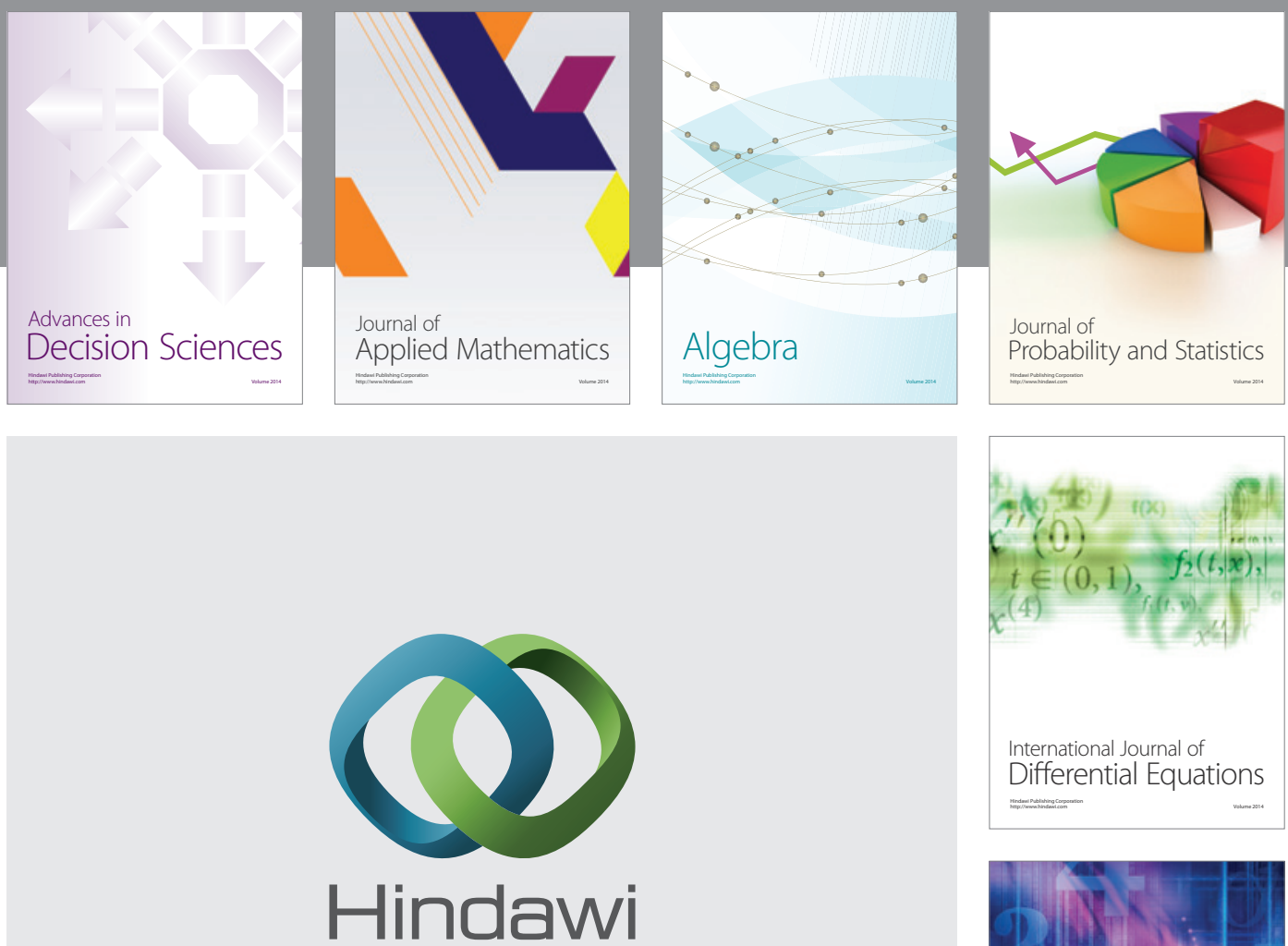

Submit your manuscripts at http://www.hindawi.com
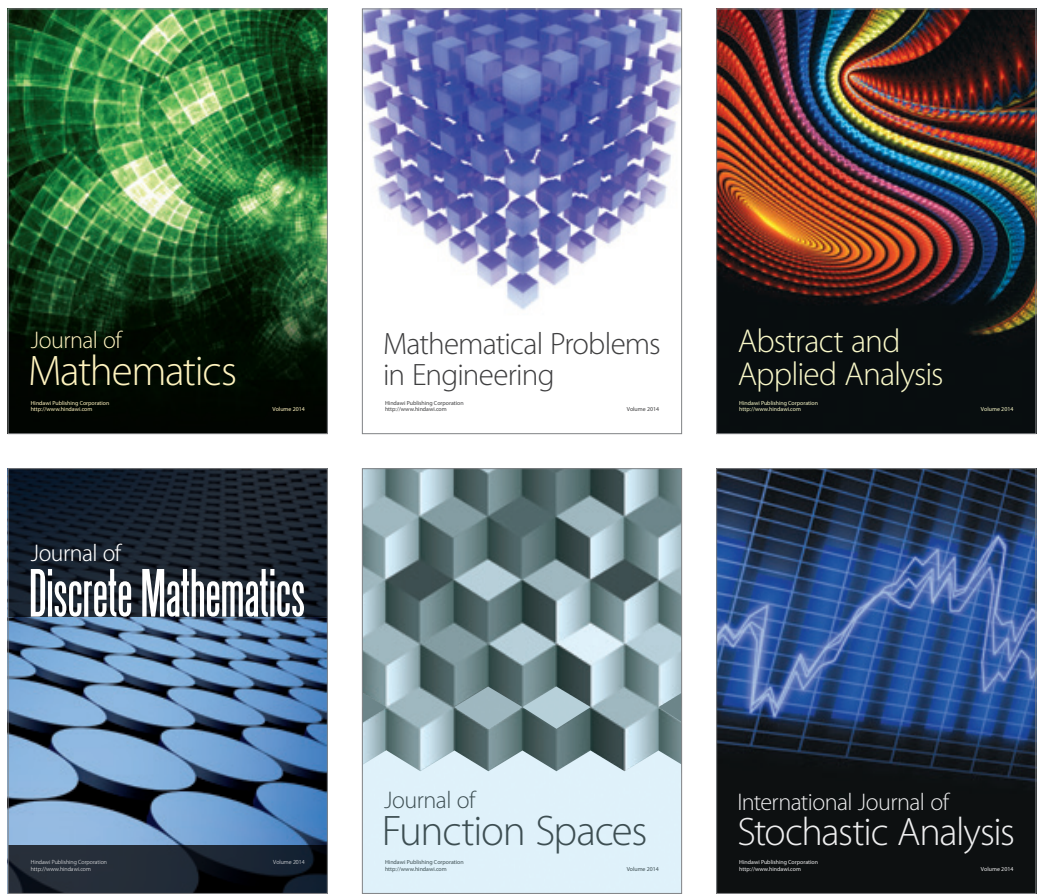

Journal of

Function Spaces

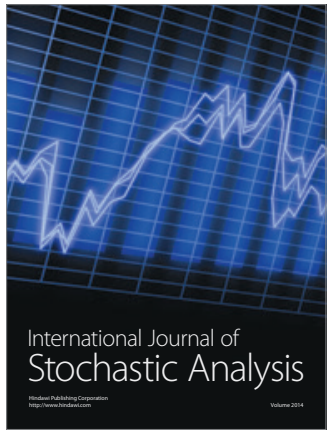

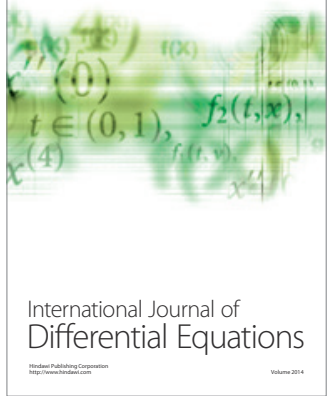
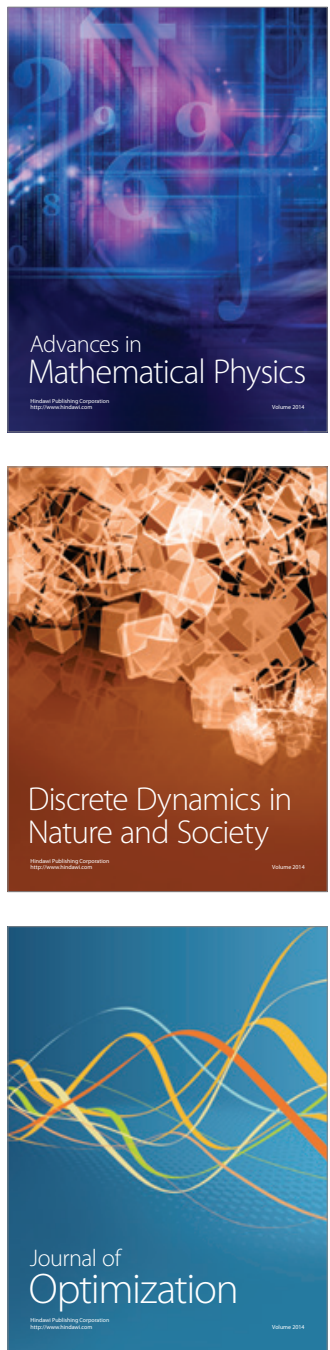